2. To: (Receiving Organization)

Distribution

5. Proj./Prog./Dept./Div.:

Characterization Project Management / Special Project Report

8. Originator Remarks:

This is the second of three special project reports prepared with supplemental funding and is being released for retrievability purposes.

11. Receiver Remarks: 11A. Design Baseline Document? [ $]$ Yes [X] No

For Release
3. From: (originating organization) Numatec Hanford Corporation/Special Analytical Support

6. Design Authority/ Design Agent/Cog. Engr.:

R. S. Viswanath
4. Related EDT No.:

$N / A$

7. Purchase Order No.:

$N / A$

9. Equip./Comporient No.:

$\mathrm{N} / \mathrm{A}$

10. System/Bldg./Facility: $N / A$

12. Major Assm. Dwg. No.: N/A

13, Permit/Permit Application No.: $\mathrm{N} / \mathrm{A}$

14. Required Response Date: $12 / 23 / 97$

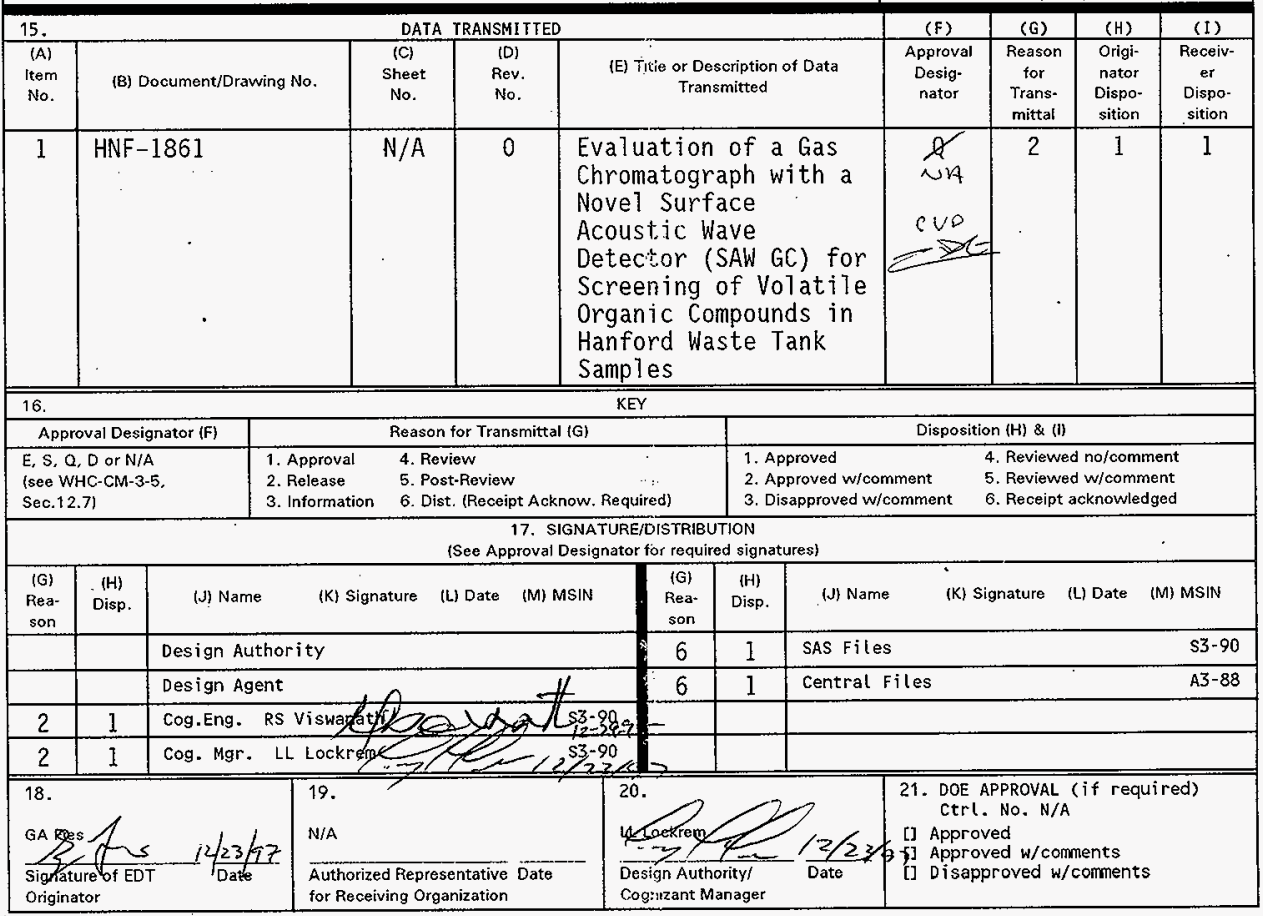




\title{
Evaluation of a Gas Chromatograph with a Novel Surface Acoustic Wave Detector (SAW GC) for Screening of Volatile Organic Compounds in Hanford Waste Tank Samples
}

\author{
L. L. Lockrem \\ Numatec Hanford Corporation, Richland, WA 99352 \\ U.S. Department of Energy Contract DE-AC06-96RL.13200
}

$\begin{array}{lll}\text { EDT/ECN: } & 620341 & \text { UC: } 2070 \\ \text { Org Code: } & 8 C 530 & \text { Charge Code: } \\ \text { B\&R Code: } & \text { EW } 3130030 & \text { Total Pages: } 83\end{array}$

Key Words: SAW GC, Surface Acoustic Wave Detector, volatile organic compounds, screening, Hanford waste tanks

Abstract: A novel instrument, a gas chromatograph with a Surface Acoustic Wave Detector (SAW GC), was evaluated for the screening of organic compounds in Hanford tank headspace vapors. Calibration data were developed for the most common organic compounds, and the accuracy and precision were measured with a certified standard. The instrument was tested with headspace samples collected from seven Hanford waste tanks.

Teflon is a trademark of E. I. du Pont de Nemours \& Co., Inc.

Windows 95 and Exce] are trademarks of Microsoft Corp.

TRADEMARK DISCLAIMER. Reference herein to any specific commercial product, process, or service by trade name, tradentark, manufacturer, or otherwise, does not necessarily constitute or imply its endorsement, recommendation, or favoring by the United States Government or any agency thereof or its contractors or subcontractors.

Printed in the United States of America. To obtain copies of this document, contact: Document Control Services, P.0. Box 950, Mailstop H6-08, Richland WA 99352, Phone (509) 372-2420;

Fax (509) 376-4989.
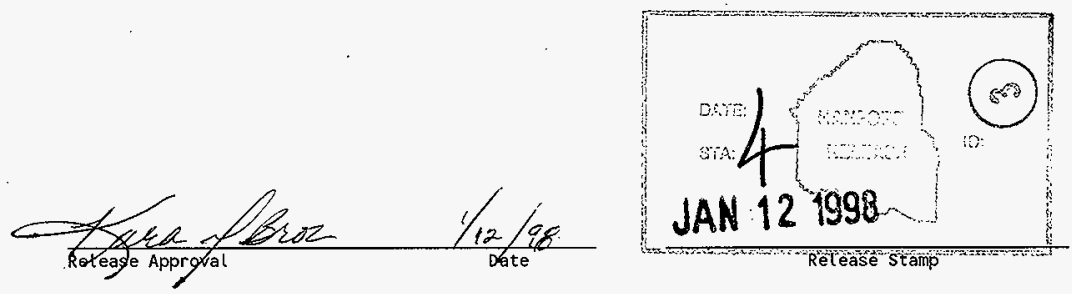

Approved for Public Release 


\section{Evaluation of a Gas Chromatograph with a Novel Surface Acoustic Wave Detector (SAW GC) for Screening of Volatile Organic Compounds in Hanford Waste Tank Samples}

\section{L. Lockrem}

Special Analytical Support

Numatec Hanford Corporation

L. A. Pingel

M. Stauffer

R. S. Viswanath

SGN Eurisys Services Corporation

Date Published

September, 1997

Prepared for the U.S. Department of Energy

Assistant Secretary for Environmental Management 
HNF-1861 Rev. 0

TABLE OF CONTENTS

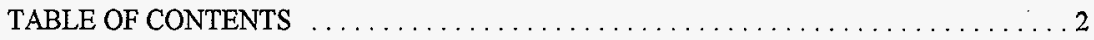

LIST OF APPENDICES $\ldots \ldots \ldots \ldots \ldots \ldots \ldots \ldots \ldots \ldots \ldots \ldots \ldots \ldots$

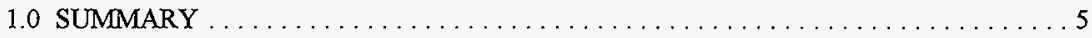

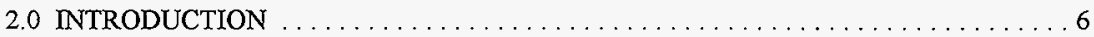

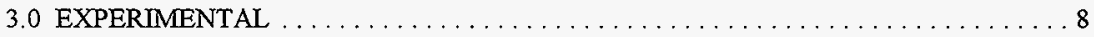

3.1 INSTRUMENT OPERATION $\ldots \ldots \ldots \ldots \ldots \ldots \ldots \ldots \ldots \ldots \ldots$

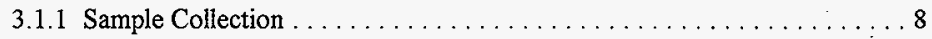

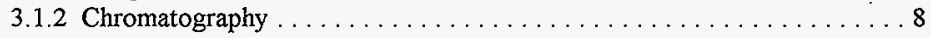

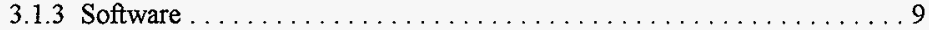

3.1 .4 Analysis Conditions $\ldots \ldots \ldots \ldots \ldots \ldots \ldots \ldots \ldots \ldots$

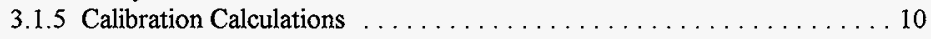

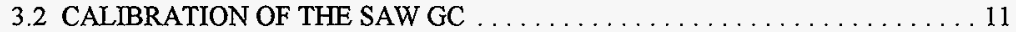

3.2 .1 Compound Selection . . . . . . . . . . . . . . . . . . . . . 11

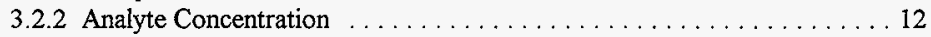

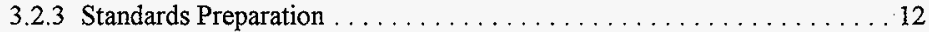

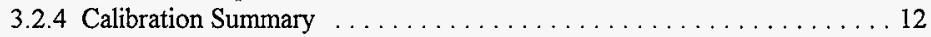

1. Tetrahydrofuran ....................... 12

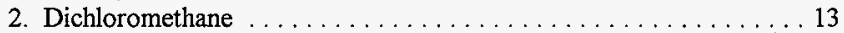

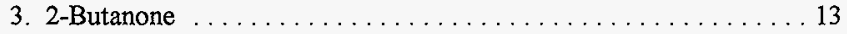

4. Benzene . . . . . . . . . . . . . . . . . . . . . 13

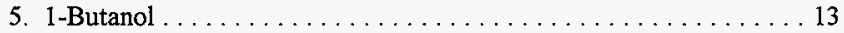

6. Methylisobutyl Ketone . . . . . . . . . . . . . . . . . 14

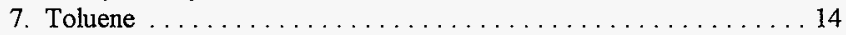

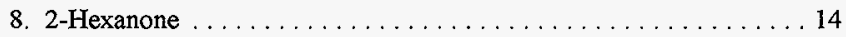

9. Chlorobenzene . . . . . . . . . . . . . . . . . . . 14

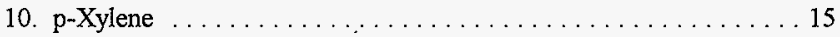

11. n-Hexane . . . . . . . . . . . . . . . . . . . . 15

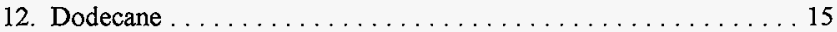

3.2 .5 Calibration Results . . . . . . . . . . . . . . . . . . . 16

3.3 ANALYSIS OF A STANDARD GAS MIXTURE $\ldots \ldots \ldots \ldots \ldots \ldots \ldots$

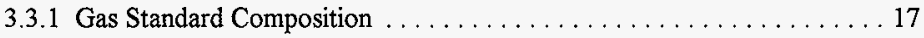

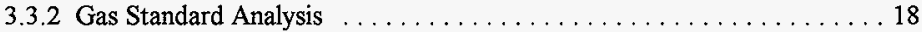

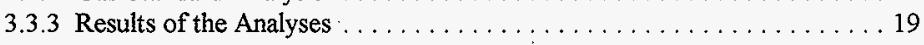


HNF-1861 Rev. 0

\section{TABLE OF CONTENTS (continued)}

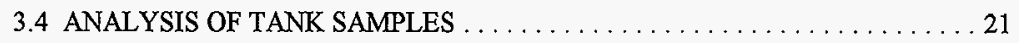

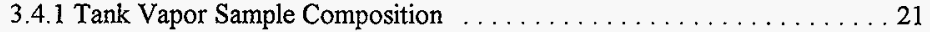

3.4 .2 Vapor Sample Analyses . . . . . . . . . . . . . . . . . . 22

3.4.3 Results of Tank Vapor Analyses ................... 22

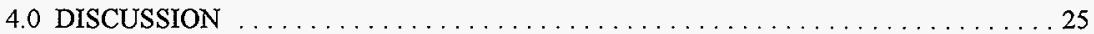

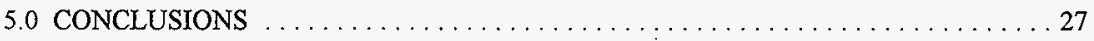

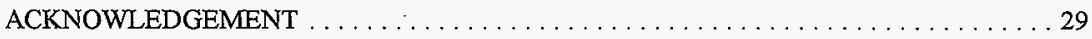

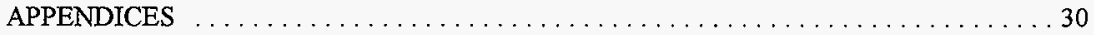


HNF-1861 Rev. 0

\section{LIST OF APPENDICES}

APPENDIX A: CALIBRATION CURVES OF ANALYTE CHEMICALS

APPENDIX B: $\quad$ ANALYSES/CHROMATOGRAMS OF NIST GAS STANDARD

APPENDIX C: $\quad$ ANALYSES/CHROMATOGRAMS OF WASTE TANK SAMPLES

APPENDIX D: $\quad$ STANDARD OPERATING PROCEDURE:

SCREENING AMBIENT ENVIRONMENTS FOR BTEX AND CHC COMPOUNDS USING GC/SAW FIELD PORTABLE

GAS CHROMATOGRAPHS

APPENDIX E: $\quad$ SOIL TESTING SUMMARY BY ELECTRONIC SENSOR TECHNOLOGY

APPENDIX F: $\quad$ SENSITIVITY AND DETECTION OF TPH-G HYDROCARBONS USING THE 4100 FIELD PORTABLE GC INCORPORATING A SURFACE ACOUSTIC WAVE DETECTOR

APPENDIX G: $\quad$ RAPID SCREENING FOR POLYCHLORINATED BIPHENYLS AND 2,3,7,8- DIOXIN IN SOIL AND FLYASH USING A SAW/GC 


\section{HNF-1861 Rev. 0}

\subsection{SUMMARY}

Special Analytical Support (SAS) evaluated the novel SAW GC instrument for the screening of organic compounds in Hanford tank headspace vapors. The evaluation was done in 3 stages:

1) Calibration data were developed for 11 organic compounds representative of the volatile organic compounds (VOCs) found in the Hanford waste tanks.

2) Using these calibrations, the instrument performance was then measured with a certified gas standard mixture, and its precision and accuracy was determined.

3) The SAW GC was finally tested with a suite of headspace samples collected from 7 Hanford waste tanks.

Precision of the SAW GC was quite good (RSD: $21 \%$ or better) but the accuracy varied considerably between the analytes (RPD: 18 to 209\%). The Method Detection Limits for most compounds was about 1 ppmv. The SAW GC did not detect any analytes in the 7 Hanford waste tank samples that had VOC concentrations from 6 to $680 \mathrm{ppbv}$. The instrument partially resolved the compounds but the high water content of the Hanford tank samples probably had a negative influence on the SAW detector. No water trap was used because it could interfere with the polar organic compounds present in most tank headspace samples. The analytical conditions used in these experiments were recommended by the vendor and no special attempt was made to optimize the instrument parameters. The SAW GC performance could probably be further improved for a specific set of samples and conditions. However, "generic" operating conditions were used because the Hanford Tank samples are highly variable in their composition.

Although the SAW GC is not ideal for screening tank headspace vapors, the instrument has some unique properties that make it useful for other applications. The high speeds of the analyses make it a good screening tool for higher concentrations ( $>1$ ppmv) of nonpolar analytes, such as chlorinated and aromatic compounds.

All project work was completed by September 30, 1997. 


\section{HNF-1861 Rev. 0}

\subsection{INTRODUCTION}

The history of portable gas chromatography (GC) instrumentation has always been restricted to the use of photoionization detectors (PIDs) and thermal conductivity detectors (TCDs). Both detectors are robust enough for field applications but have a limited range of compounds that can be analyzed at trace level concentrations. Other detectors used for field GC analysis are either too frail to be used in the harsh field environment, require excessive support, or are too chemicalspecific to be useful for field applications.

The SAW-GC consists of a GC optimized for the high speed separation of compounds and a novel detector. This detector is called a surface acoustic wave sensor (SAW Sensor ${ }^{\mathrm{TM}^{\mathrm{l}}}$ ) and the entire instrument is a 'SAW GC'. This unique detector works on the concept that an electric field applied to a piezoelectric crystal generates a sound wave of specific frequency on its surface. Adsorption of analytes onto the crystal changes the mass and therefore the frequency of the surface acoustic wave. In the SAW detector, the frequency of the sensor crystal is compared to a reference frequency value and is monitored by the controlling software. As an analyte exits the GC column, it momentarily adsorbs to the surface of the crystal, changing the mass of the crystal. The momentary change in the crystal mass changes its frequency. This is compared to the reference frequency and the difference is plotted as a chromatographic peak.

The Tank Waste Remediation System (TWRS) group of Lockheed Martin Hanford Corporation requested that SAS evaluate the capabilities of this new type of analytical sensor developed by Electronic Sensor Technology ${ }^{2}$ (EST). The instrument developed by EST uses a SAW sensor in conjunction with a high speed field GC. EST configured the instrument to measure VOCs in waste tanks located on the Hanford Site.

1 Trademark of Electronic Sensor Technology

Westlake Village, CA

2 Electronic Sensor Technology

2301 Townsgate Road

Westlake Village, CA 91361

(805) 489-1994 


\section{HNF-1861 Rev, 0}

Testing of the SAW-GC for application in the Tank Vapor Characterization Program consisted of 3 stages:

1) Calibration: Calibration curves were generated for 12 compounds using the SAW-GC in a vendor recommended configuration for volatile organic compound analyses. The compounds were selected from available data on the most common chemical constituents of the tank headspaces.

2) Validation with a certified gas mixture: Using the calibration data, the instrument was tested with the analysis of a certified gas standard mixture, and the precision and accuracy of the measurements were determined.

3) Testing with Hanford tank samples: The instrument was finally challenged with a suite of 7 SUMMA $^{3}$ samples collected from the headspace of Hanford underground storage tanks. The samples were selected at random and are representative of the compositional and physical characteristics of Hanford tank vapor samples.

${ }^{3}$ SUMMA is a trademark of Molectrics, Inc., Cleveland, $\mathrm{OH}$. 


\section{HNF-1861 Rev. 0}

\subsection{EXPERIMENTAL}

\subsection{INSTRUMENT OPERATION}

A general instrument operating procedure for analyzing volatile organic compounds in vapor samples can be found in Appendix D: Standard Operating Procedure: Screening Ambient Environments for BTEX and CHC Compounds using GC/SAW Field Portable Gas

Chromatographs. In Appendix E, the procedure Soil Testing by Electronic Sensor Technology extends this technique to the analysis of VOC in soil samples. The special application of the SAW GC to the analysis of Leaking Underground Fuel Tanks (LUFT) is described in Appendix F: Sensitivity and Detection of TPH-g Hydrocarbons using the 4100 Field Portable GC Incorporating a Surface Acoustic Wave Detector. In Appendix G, Rapid Screening for Polychlorinated Biphenyls and 2,3,7,8 Dioxin in Soil and Flyash using SAW/GC shows the potential of the SAW GC instrument for the analysis of semivolatile compounds.

The following is a discussion of the operational parameters as they were relevant to the analysis of Tank Vapor samples.

\subsubsection{Sample Collection}

The SAW GC has a sampling pump that loads an internal Tenax ${ }^{4}$ trap with the sample for a specified time at a known rate. After the sample is collected onto the trap, a valve rotates placing the trap into the carrier gas stream. The trap is heated to about $200{ }^{\circ} \mathrm{C}$ releasing the collected sample into the SAW GC.

\subsubsection{Chromatography}

The nature of the SAW GC as a screening tool allows for a very short column. The column length is usually $50 \mathrm{~cm}$. Thus retention times of 20 seconds or less are expected. Upon injection, the column is heated to approximately $80^{\circ} \mathrm{C}$ at a rate of $3{ }^{\circ} \mathrm{C} / \mathrm{sec}$. The carrier gas moves the sample aliquot through the column separating it into its various components. The sample elutes from the column directly onto the sensor.

${ }^{{ }^{5}}$ Tenax is a trademark of Enka Research Institute, Arnhem, The Netherlands. 


\section{HNF-1861 Rev. 0}

\subsubsection{Software}

The SAW GC requires a portable PC as a means of collecting and storing the collected data. The PC software that controls the instrument and calculates the frequency shift is the vendor developed MicroSense 3.4 ${ }^{5}$. The software stores the collected data and controls all timed events.

\subsubsection{Analysis Conditions}

The conditions used for the analysis of the VOCs in tank vapor samples were suggested by the instrument vendor; see Table 1. No special attempt was made to optimize these operating parameters.

Table 1: Instrument Analysis Conditions

\begin{tabular}{|l|l|}
\hline Sampling Flow Rate & $27 \mathrm{ml} / \mathrm{min}$ \\
\hline Column & $\begin{array}{l}\mathrm{DB}-624,50 \mathrm{~cm} \times 0.32 \mathrm{~mm}, 0.25 \mathrm{um} \text { film } \\
\text { thickness }\end{array}$ \\
\hline Column Temperature & $\begin{array}{l}\text { initial } 40^{\circ} \mathrm{C} \\
\text { then } 3^{\circ} \mathrm{C} / \mathrm{sec} \\
\text { to } 85^{\circ} \mathrm{C} \text { final }\end{array}$ \\
\hline Detector & Surface Acoustic Wave Sensor \#139 \\
\hline $\begin{array}{l}\text { Heated Zones: } \\
\text { Sensor } \\
\text { Valve } \\
\text { Inlet }\end{array}$ & $\begin{array}{l}{ }^{\circ} \mathrm{C}^{1} \\
70^{\circ} \mathrm{C} \\
80^{\circ} \mathrm{C}\end{array}$ \\
\hline VCO Frequency & $500.180 \mathrm{~Hz}$ \\
\hline Turnover Frequency & $500.170 \mathrm{~Hz}$ \\
\hline Retention Time Window & $2.5 \%$ \\
\hline
\end{tabular}

1) Note: The temperature of the SAW sensor was kept as low as possible for best sensitivity.

5 Copyright of Electronic Sensor Technology, Westlake Village, CA 


\section{HNF-1861 Rev. 0}

\subsubsection{Calibration Calculations}

To set up the system for calculating the concentration of an analyte peak, a value referred to as the 'scale factor' must be determined and entered into the method. The scale factor has the following units:

$$
\begin{array}{r}
\text { Scalefactor } \frac{\Delta \mathrm{Hz}}{(\text { Conc }[\mathrm{ppm}])(\text { SampleSize }[\mathrm{ml}])} \\
\text { Equation 1: Scale Factor Units }
\end{array}
$$

Calibration of the SAW GC can be accomplished using a multipoint calibration curve where the slope of the curve is used to determine a scale factor, as in equation 2 :

$$
\text { ScaleFactor }=\frac{\left(\text { Calcurveslope }\left[\frac{H z}{\text { Conc }}\right]\right)}{\left(\text { FlowRate }\left[\frac{\mathrm{ml}}{\mathrm{min}}\right]\right)(\text { SampleTime [min]) }}
$$

Equation 2: Scale Factor Calculations using the Slope of Calibration Curve

The calibration of the SAW GC for screening can also be accomplished using a single calibration point, as in equation 3 :

$$
\text { ScaleFactor }=\frac{(\Delta H z)}{\left(\operatorname{Conc}\left[\frac{u I}{I}\right]\right)\left(\text { FlowRate }\left[\frac{m I}{\min }\right]\right)(\text { SampleTime }[\mathrm{min}])}
$$

\section{Equation 3: Scale Factor Calculations using Single Point Calibration}

For the initial calibration of each analyte, a multipoint calibration curve is desirable. A single point is used for field checking the calibration. 


\section{HNF-1861 Rev. 0}

\subsection{CALIBRATION OF THE SAW GC}

\subsubsection{Compound Selection}

The purpose of this study was to test the screening abilities of the SAW GC for organic compounds typical of Hanford underground storage tanks. The compounds for the calibration were selected from available data on the composition of the tanks (TO-14 analysis results). 12 compounds were picked because of their abundance in many tank samples and because they represent a range of chemical and physical characteristics (polarity, boiling points, etc.). The following compounds were analyzed as vapors at various concentrations for instrument calibration, to determine the linear range, and to estimate their method detection limits (MDLs).

Table 2: Analytes Used for SAW GC Calibration

\begin{tabular}{|l|l|}
\hline Compound Name & CAS Number \\
\hline Tetrahydrofuran & $109-99-9$ \\
\hline Dichloromethane & $75-09-2$ \\
\hline 2-Butanone & $78-93-3$ \\
\hline Benzene & $71-43-2$ \\
\hline 1-Butanol & $71-36-3$ \\
\hline Methylisobutyl ketone & $108-10-1$ \\
\hline Toluene & $108-88-3$ \\
\hline 2-Hexanone & $591-78-6$ \\
\hline Chlorobenzene & $108-90-7$ \\
\hline Hexane & $110-54-3$ \\
\hline p-Xylene & $106-42-3$ \\
\hline n-Dodecane & $112-40-3$ \\
\hline
\end{tabular}




\section{HNF-1861 Rev. 0}

\subsubsection{Analyte Concentration}

The standard concentration was corrected to Standard Temperature and Pressure (STP) according to the following formula:

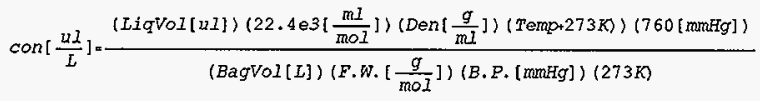

\section{Equation 4: Determining the Concentration of Bag Sample}

\subsubsection{Standards Preparation}

Standards were prepared as recommended by the vendor; a precise volume of analyte was dissolved in acetone, then injected into a sample bag, and allowed to evaporate. Acetone is very volatile and is not adsorbed onto the SAW detector crystal, and, therefore, does not produce a detector signal. A small amount of heat (about $30^{\circ} \mathrm{C}$ ) was applied to the bag to force total evaporation. A sample bag was used to allow the analyte to be at atmospheric pressure during analysis. The contents of the bag were analyzed by piercing the septum on the sample bag with the syringe needle of the SAW GC inlet.

\subsubsection{Calibration Summary}

Calibration curves for the selected compounds are in Appendix A. Some compounds do not have a calibration curve because they were not detected under the analytical conditions (e.g. dichloromethane), coeluted with other compounds (tetrahydrofuran), or were excessively retained on the SAW detector (n-dodecane). Furthermore, the concentration ranges differ between some compounds because they were difficult to detect at very low concentrations or showed nonlinear detector response at very high concentrations. The following is a compound by compound discussion of the calibration results:

1. Tetrahydrofuran

Retention Time: $2.0 \mathrm{sec}$

The retention time for tetrahydrofuran (THF) is close to that of water.

This makes the 2 compounds indistinguishable under the analysis conditions. To alleviate this problem, a vendor supplied water trap was used to stop water interference. This allowed measurement of THF and a retention time was noted. However, a water trap could not be used for the 


\section{HNF-1861 Rev. 0}

analysis of compound mixtures because it also removed polar analytes from the sample.

2. Dichloromethane

Retention Time: $2.2 \mathrm{sec}$

The retention time of dichloromethane is close to that of water. Therefore, it can only be seen as a chromatographic peak if its peak area greatly exceeds that of water or a water trap is used.

3. 2-Butanone

Retention Time: $3.13 \mathrm{sec}$

Scale Factor $\quad 0.64$

Slope $\quad 4.3$

$$
\begin{aligned}
& \text { y-Intercept } \quad 84 \\
& r^{2}=0.983
\end{aligned}
$$

The 2-butanone peak elutes on the shoulder of the water peak. This makes it difficult to detect trace concentrations of this compound.

4. Benzene

Scale Factor $\quad 0.37$

Slope

Retention Time: $3.85 \mathrm{sec}$

$$
\begin{aligned}
& y \text {-Intercept } \\
& \mathrm{r}^{2}=0.762
\end{aligned}
$$

Benzene showed good linearity and reproducibility over short time periods (1 day). However, the response changed over longer time intervals (several days) producing a calibration curve with the same slope but parallel to the original curve. The software does not allow to compensate for daily fluctuations in detector sensitivity such as the use of relative response factors.

5. I-Butanol

Scale Factor 10.62

Slope

Retention Time: $4.51 \mathrm{sec}$

$$
\begin{aligned}
& y \text {-Intercept } \\
& \mathrm{r}^{2}=0.955
\end{aligned}
$$

There were some initial problems when analyzing high concentrations of butanol. This was probably due to carry-over of some residual material causing erratic peaks in the proceeding analyses. Butanol, a polar 


\section{HNF-1861 Rev, 0}

compound, is strongly retained on interior cold surface of the GC. This problem was resolved by baking the trap, column, and sensor after every analysis containing high concentrations.

6. Methylisobutyl Ketone

Scale Factor 2.80

Slope
Retention Time: $5.52 \mathrm{sec}$

$$
\begin{aligned}
& \text { y-Intercept } \quad 818 \\
& \mathrm{r}^{2}=0.993
\end{aligned}
$$

Methylisobutyl ketone showed reasonably good linearity and reproducibility in the range from 10 to $145 \mathrm{ppmv}$. At higher concentrations, the calibration curve had a different slope.

7. Toluene

Scale Factor 4.05

Slope

Toluene displayed a good linear response in the range from 10 to 110 ppmv.

$$
\text { y-Intercept } 578
$$$$
r^{2}=0.952
$$

8. 2-Hexanone

Scale Factor 21.5

Slope
Retention Time: $7.10 \mathrm{sec}$

2-Hexanone showed good linearity but the calibration curve does not go through the origin. This could be caused by carry-over from this moderately polar compound.

9. Chlorobenzene

Retention Time: $7.80 \mathrm{sec}$

Scale Factor 28.9

Slope $\quad 195$

$$
\begin{aligned}
& y \text {-Intercept } 2229 \\
& r^{2}=0.975
\end{aligned}
$$


10. $p$-Xylene

$\begin{array}{ll}\text { Scale Factor } & 30.0 \\ \text { Slope } & 394\end{array}$

Retention Time: $8.93 \mathrm{sec}$

$$
\text { y-Intercept } 2530
$$$$
r^{2}=0.975
$$

p-Xylene was used as an analyte but all xylene isomers had similar retention times. They showed a linear response in the range from 5 to $40 \mathrm{ppmv}$ but the slope increased at higher concentrations.

11. $n$-Hexane

Retention Time: $15.1 \mathrm{sec}$

Hexane elutes very late as a broad peak. This peak gets successively larger, both in width and height, as the concentration of hexane increases. The software often does not detect this change in the baseline especially at low concentrations. At a concentration of $40 \mathrm{ppmv}$, the software reproducibly detects the changing baseline, thus identifying the hexane peak. However, the peak at 15 seconds cannot be exclusively identified as hexane in mixtures. A peak with this retention time is seen in samples that do not contain hexane. This is due to coelution with other late eluting compounds similar to the water peak.

12. Dodecane

Dodecane was very slow in eluting and exceeded the programmed run time. According to the manufacturer, the configuration of the SAW GC chosen for this study was not suitable for the analysis of higher boiling compounds, such as dodecane.

13. Water

Retention Time: $1.8 \mathrm{sec}$

Water was not a target analyte but it produces a predominant peak in all samples at the front of the chromatogram. Because of this, it poses a special problem that affects the analysis of other compounds with very short retention times. No water trap was used in this case because it interferes with other polar compounds and creates excessive dead volume when sampling. 


\section{HNF-1861 Rev. 0}

Water was seen in all ambient air and tank headspace samples as a significant peak. Therefore, a special effort was made to understand the effects of water on other analytes. A sample bag was filled with $1.0 \mathrm{~L}$ of room air and analyzed with the SAW GC and the standard method. The resulting water peak was noted at 1.8 seconds, as expected. A water saturated air sample was then prepared by filling the same sample bag with $1.0 \mathrm{~L}$ of room air and $5 \mathrm{ul}$ distilled water. A small amount of heat was applied to the bag to evaporate the visible water droplets. It is assumed that the bag sample reached $100 \%$ relative humidity. The contents were analyzed as before. The resulting water peak did not show any increase in size in comparison to the room air sample. This experiment could indicate that water is strongly retained on the crystal surface and quickly saturates the detector. It then desorbes from the detector and produces a tailing peak that often interferes with other compounds with a short retention time.

\subsubsection{Calibration Results}

Retention Time: The analytes used for the calibration had different retention times that allowed discrete retention time windows for each peak without overlap. However, it was found that with increasing concentration of an analyte, the apex of the peak shifted slightly and, therefore, its retention time also increased. This had the effect of sometimes causing the analyte to be identified incorrectly as the proceeding peak. It was necessary during calibration to use a correction in the retention time window as the concentration of an analyte increased. Similarly, it was noted during the daily calibration checks that there was some daily shift in the peak retention times which caused an occasional misidentification of a peak. This problem was minor when using concentrations of a compound near the midpoint of its retention time window.

Linear Range: The linear range of the SAW GC was examined in the range from approximately 1 to $300 \mathrm{ppmv}$. It was found that some analytes did not show a good linear calibration curve; as the concentration of some analytes increased, flattening of the curve was experienced. For most analytes, the range from 10 to $150 \mathrm{ppmv}$ is reasonably linear. The actual tank samples analyzed by SAW GC had low concentrations of organic analytes; they were near the lower end of the SAW sensor's sensitivity and close to the estimated MDL of about 1 ppmv. Table 3 shows there is a rough relationship between the boiling point of a compound and its y-intercept. It suggests this nonlinearity at low concentration, especially for high boiling compounds, could be related to carry-over from these analytes.

Sensitivity: Retention of an analyte on the SAW crystal detector, its "stickiness", is generally a function of the vapor pressure and is roughly related to the boiling point of the 


\section{HNF-1861 Rev, 0}

compound. Examination of the calibration data shows the lower boiling compounds (benzene, 2-butanone) have calibration curves with a lower slope than the higher boilers (2-hexanone, xylene); see Table 3 . Very low boilers such as chloromethane do not produce a signal at all because of their lack of "stickiness". This change in the calibration slope affects the sensitivity, the counts per sample unit, for different compounds. This suggests the SAW GC is generally more sensitive for higher boiling compounds.

Table 3: Boiling Point and Calibration Relationships for Analytes

\begin{tabular}{|l|l|l|l|}
\hline Compound Name & $\begin{array}{l}\text { Boiling } \\
\text { Point }\left({ }^{\circ} \mathbf{C}\right)\end{array}$ & Intercept & Slope \\
\hline 2-Butanone & 79.6 & 84 & 43 \\
\hline Benzene & 80.1 & 180 & 3 \\
\hline Toluene & 110.6 & 578 & 27 \\
\hline Methyl-isobutylketone & 116.8 & 818 & 19 \\
\hline n-Butanol & 117 & 341 & 14 \\
\hline 2-Hexanone & 128 & 2229 & 146 \\
\hline Chlorobenzene & 132 & 510 & 195 \\
\hline Xylene & 144 & 2530 & 394 \\
\hline
\end{tabular}

Method Detection Limits: The detection limits of the analytes varied with retention time. The standard test for determination of the method detection limit (MDL) uses the $\mathrm{t}$-test value and the standard deviation of a series of measurements. Peaks proceeding water generally had a calculated MDL of about $1 \mathrm{ppm}$.

\subsection{ANALYSIS OF A STANDARD GAS MIXTURE}

\subsubsection{Gas Standard Composition}

To validate the calibration of the SAW GC, a NIST traceable gas standard was analyzed. The gas standard was prepared and certified by Scott-Marrin, Riverside, CA (certificate \# CC68664). 
HNF-1861 Rev. 0

The compounds were selected to represent a range of chemical and physical characteristics such as boiling points and polarities; see Table 4 .

Table 4: Composition and Concentration of NIST-Traceable Gas Standard

\begin{tabular}{|l|l|}
\hline Compound & Certified Concentration \\
\hline Chloromethane & $1.009 \mathrm{ppm}$ \\
\hline Tetrahydrofuran & $1.009 \mathrm{ppm}$ \\
\hline $\mathrm{n}$-Pentane & $1.096 \mathrm{ppm}$ \\
\hline Methyl-isobutylketone & $1.020 \mathrm{ppm}$ \\
\hline Chlorobenzene & $1.055 \mathrm{ppm}$ \\
\hline $1,2,4-$ Trimethylbenzene & $0.605 \mathrm{ppm}$ \\
\hline
\end{tabular}

\subsubsection{Gas Standard Analysis}

The gas sample was analyzed under the same operating conditions as those used for the instrument calibration (see Table 1). A $1 \mathrm{~L} \mathrm{Tedlar}{ }^{6}$ sample bag was cleaned by repeated evacuation and filling with ultrapure air. Then, the bag was filled from a high pressure aluminum cylinder ( $2000 \mathrm{psig}$ ) containing the gas standard. Using a bag for sampling ensured that the gas mixture was at ambient pressure. The gas sample was immediately analyzed by SAW GC. It can be assumed that the sample from the gas cylinder was essentially dry. No attempt was made to humidify the sample to match the matrix of the tank vapor samples. The absence of water reduced the interference with other early eluting peaks such as tetrahydrofuran. This compound cannot be measured in the presence of significant concentrations of water. Therefore, water was removed as a target compound and the retention time window was adjusted for tetrahydrofuran as a target compound. Analysis of the standard gas mixture was repeated 10 times to determine the precision and accuracy of the analyses, and to monitor any trends in the peak areas during repeated analyses.

${ }^{6}$ Tedlar is a trademark of E. I. du Pont de Nemours \& Co., Inc. 
HNF-1861 Rev, 0

\subsubsection{Results of the Analyses}

The analytical results for the 10 analyses of the 6 component gas standard are presented in Table 5. The precision and accuracy for the available data are shown in Table 6. Chromatograms for the 10 analyses are in Appendix B.

Table 5: Results of the Analysis of NISTGas Standard

\begin{tabular}{|l|l|l|l|l|l|l|}
\hline File ID & \multicolumn{2}{|c|}{ THF } & \multicolumn{2}{|c|}{$\begin{array}{l}\text { Methyl- } \\
\text { isobutyl- } \\
\text { ketone }\end{array}$} & \multicolumn{2}{l|}{$\begin{array}{l}\text { Chloro- } \\
\text { benzene }\end{array}$} \\
\hline & $\begin{array}{l}\text { Retention } \\
\text { Time } \\
\text { (sec) }\end{array}$ & $\begin{array}{l}\text { Concen- } \\
\text { tration } \\
\text { (ppmv) }\end{array}$ & $\begin{array}{l}\text { Retention } \\
\text { Time (sec) }\end{array}$ & $\begin{array}{l}\text { Concen- } \\
\text { tration } \\
\text { (ppmv) }\end{array}$ & $\begin{array}{l}\text { Retention } \\
\text { Time } \\
\text { (sec) }\end{array}$ & $\begin{array}{l}\text { Concen- } \\
\text { tration } \\
\text { (ppmv) }\end{array}$ \\
\hline \hline 91912.21 & 1.7 & ND & 5.36 & ND & 7.86 & 1.4 \\
\hline 91912.25 & 1.7 & ND & 5.38 & ND & 7.90 & 1.4 \\
\hline 91912.27 & 1.7 & ND & 5.34 & 2.1 & 7.86 & 1.4 \\
\hline 91912.29 & 1.7 & 0.68 & 5.42 & 2.3 & 7.90 & 1.4 \\
\hline 91912.31 & 1.7 & 0.62 & 5.40 & 3 & 7.90 & 1.4 \\
\hline 91912.33 & 1.7 & 0.64 & 5.42 & 3.8 & 7.96 & 1.3 \\
\hline 91912.35 & 1.7 & 0.73 & 5.40 & 2.9 & 7.90 & 1.4 \\
\hline 91912.37 & 1.7 & 0.95 & 5.40 & 3.4 & 7.94 & 1.4 \\
\hline 91912.39 & 1.7 & 1.00 & 5.36 & 3.6 & 7.90 & 1.3 \\
\hline 91912.41 & 1.7 & 1.10 & 5.40 & 3.8 & 7.94 & 1.4 \\
\hline
\end{tabular}

Note:

$\mathrm{ND}=$ Peak was not detected by software. 
HNF-1861 Rev, 0

Table 6: Precision and Accuracy of the Analyses

\begin{tabular}{|l|l|l|l|}
\hline & THF & $\begin{array}{l}\text { Methyl-iso- } \\
\text { butylketone }\end{array}$ & Chlorobenzene \\
\hline $\begin{array}{l}\text { Average } \\
\text { Concentration }\end{array}$ & $0.819 \mathrm{ppmv}$ & 3.11 & $1.38 \mathrm{ppmv}$ \\
\hline $\begin{array}{l}\text { Standard } \\
\text { Deviation }\end{array}$ & 194 & 0.66 & 0.04 \\
\hline \% RSD & $0.24 \%$ & $21.1 \%$ & 0.03 \\
\hline \% Difference & $-18 \%$ & $209 \%$ & $38 \%$ \\
\hline
\end{tabular}

Comparison of Tables 2 and 3 shows, from the 11 compounds used in the calibration of the SAW GC, there are 3 analytes contained in the standard gas mixture: Tetrahydrofuran (THF), methylisobutyl ketone, and chlorobenzene. With the retention windows from all the calibration compounds stored in the operating software, the SAW GC correctly identified THF, methylisobutyl ketone, and chlorobenzene (Table 4). Of the remaining 3 compounds in the mixture, chloromethane could not be detected with the SAW GC because of the very high volatility of this compound (boiling point: $-24.2^{\circ} \mathrm{C}$ ). 1,2,4-trimethylbenzene on the other hand presents a problem because of its high boiling point (b.p.: $169^{\circ} \mathrm{C}$ ). The SAW GC has been extensively used for the analysis of semivolatile compounds such as PCBs (see Appendix G), but the instrument has to be especially configured for this purpose. The chromatograms show additional peaks at 12.50 and 14.8 seconds. It is possible that the peak at 12.5 seconds represents n-pentane. During calibration of the SAW GC, it was noted that the higher boiling homolog nhexane had a retention time of approximately 15 seconds. In this analysis, the peak at 14.8 is identified as hexane by the software. However, there was no hexane in the standard gas sample.

THF showed acceptable precision and accuracy. Examination of the data shows an apparent increase in the concentration of THF with increasing run number. This shift was not observed previously because the calibration samples contained a significant amount of water which tended to mask the THF peak. It could indicate carry-over of the polar THF analyte. The method needs to be optimized (higher trap and inlet temperatures) to allow the reproducible analysis of THF. Methyl isobutylketone had fairly good precision (21\%), but the results were much higher than the certified value. Recalibration and a second analysis of the samples gave similar results. The measured concentrations increase with the analysis cycles, probably due to carry-over. 
Chlorobenzene showed good precision (0.03\%) and accuracy (38\%). The error in accuracy can be attributed to experimental error in the generation of standards used for the calibration.

\subsection{ANALYSIS OF TANK SAMPLES}

\subsubsection{Tank Vapor Sample Composition}

The screening potential of the SAW GC was evaluated in this third phase with samples from the Hanford underground storage tanks. The samples were headspace samples collected from the tanks in SUMMA canisters. Seven SUMMA samples were selected at random and are representative of the compositional and physical characteristics of tank vapor samples.

The headspace samples had been collected by Tank Farm operators and SAS using the In Situ Vapor Sampling System (ISVSS). The samples were collected and stored in SUMMA canisters. SUMMA canisters are stainless steel, spherical canisters having an electropolished interior surface considered chemically inert. The SUMMA samples were slightly pressurized with ultrapure air to facilitate extraction of the samples for analysis. The amount of dilution from pressurizing the sample canisters is represented by the dilution factors. Table 7 lists the vapor samples used in the SAW GC measurements.

Table 7: Hanford Waste Tank Samples Used for SAW GC Measurements

\begin{tabular}{|l|l|l|l|}
\hline Waste Tank ID & Sample Number & Dilution Factor & Sampling Date \\
\hline SX-107 & V7019-A05-077 & 2.16 & $5 / 19 / 97$ \\
\hline SX-111 & V7020-A05-055 & 2.10 & $5 / 22 / 97$ \\
\hline SX-112 & V7022-A05-041 & 1.67 & $6 / 18 / 97$ \\
\hline SX-114 & V7023-A05-080 & 1.64 & $6 / 25 / 97$ \\
\hline SX-108 & V7029-A05-074 & 1.63 & $7 / 16 / 97$ \\
\hline SX-110 & V7030-A05-079 & 1.63 & $7 / 30 / 97$ \\
\hline TX-113 & V7032-A05-084 & 1.62 & $8 / 06 / 97$ \\
\hline
\end{tabular}




\section{HNF-1861 Rev, 0}

\subsubsection{Vapor Sample Analyses}

The SUMMA canisters were analyzed previously by SAS for trace organic content using a modified US EPA TO-14 method. The samples were analyzed by SAW GC using the same parameters as in the calibration (see Table 1). The instrument was first challenged with the 6 component gas standard to check instrument performance and calibration. A sample aliquot was bled from the SUMMA canister into a $1 \mathrm{~L}$ Tedlar bag; this ensured the sample was at ambient pressure for the analysis. The sample bag has a septum port used for sampling with the SAW GC. At least 2 blank runs were made before sample analysis until the baseline was stable. The internal Tenax trap was loaded with the sample by activating the sampling pump for 15 seconds. The trap was heated ballistically and the sample was introduced into the GC. The analysis was repeated 3 times for each sample to assure reproducible data.

\subsubsection{Results of Tank Vapor Analyses}

The results from the TO-14 analyses of the Hanford tank vapor samples are listed in Table 8 .

Compounds with existing calibration data for the SAW GC are flagged $\left({ }^{*}\right)$. The data obtained by analyzing the same samples with the SAW GC are in Table 9. Chromatograms for the SAW GC analyses are in Appendix C. None of the SAW GC analyses detected target analytes in the Hanford tank samples. 
HNF-1861 Rev. 0

Table 8: Results of TO-14 Analyses (in ppbv)

\begin{tabular}{|l|l|l|l|l|l|l|l|}
\hline COMPOUND & SX-107 & SX-111 & SX-112 & SX-114 & SX-108 & SX-110 & TX-113 \\
\hline Acetone & 22 & 5.1 & & 8.8 & 9.7 & 9.8 & 270 \\
\hline 2-Butanon* & 6 & & & & & & \\
\hline Toluene* & & 6.4 & & 9.2 & 20 & & 17 \\
\hline 3-Methyl-hexane & & 16 & & 13 & 6.5 & & \\
\hline Heptane & & 6.2 & & 8.8 & & & \\
\hline m,p-Xylene & & & 24 & & 5.8 & & \\
\hline Freon 11 & & & 7.3 & & & & 680 \\
\hline n-Pentane & & & 7.9 & & & & \\
\hline Dichloromethane* & & & 8.2 & & & & \\
\hline Butanal & & & 36 & & & & \\
\hline 2-Butanone* & & & 7.9 & & & & 22 \\
\hline Chloroform & & & 8.2 & & & & 7.3 \\
\hline Carbontetrachloride & & & 36 & & & & 290 \\
\hline 1,4-Dioxane & & & 24 & & & & \\
\hline 1-Butano* & & & & & & & 220 \\
\hline Ethanol & & & & & & & 45 \\
\hline 2-Propanol & & & & & & & 90 \\
\hline 1-Propanol & & & & & & & 31 \\
\hline Tetrahydrofuran* & & & & & & & 14 \\
\hline
\end{tabular}


HNF-1861 Rev. 0

Table 9: Results of SAW GC Waste Tank Analyses

\begin{tabular}{|l|l|}
\hline Waste Tank ID & Analytes Detected \\
\hline SX-107 & None \\
\hline SX-111 & None \\
\hline SX-112 & None \\
\hline SX-114 & None \\
\hline SX-108 & None \\
\hline SX-110 & None \\
\hline TX-113 & None \\
\hline
\end{tabular}




\section{HNF-1861 Rev, 0}

\subsection{DISCUSSION}

There are 6 common compounds which occur in the tank samples and also have calibration data for the SAW GC. The concentrations of these 6 compounds in the tank samples ranged from 6 to $220 \mathrm{ppbv}$. However, the method detection limits of the SAW GC for these compounds were determined to be approximately $1 \mathrm{ppmv}$ and the calibration range was approximately 10 to 150 ppmv. This leads to the conclusion that the VOC concentrations of the 7 Hanford tank samples were at least 10 times too dilute to give useful compositional data by SAW GC analysis.

Examination of the chromatograms from the tank samples (Appendix C) shows the SAW GC resolved several components. The chromatogram for tank TX-113, a sample with 4 compounds in concentrations above $200 \mathrm{ppbv}$, did show at least 4 peaks. However, it is apparent that the peaks are much less resolved than during calibration and validation with the standard gas mixture (Appendix B). An obvious explanation for this observation is the tank samples have a different sample matrix. Table 10 lists the concentrations of permanent gases in Fanford tank TX-113. The data show the tank has moderately high concentrations of water and ammonia but is relatively low in the other analytes. This leads to the conclusion the elevated level of water vapor in the Hanford waste tanks is probably the reason for the generally poor resolution of the SAW GC chromatograms. This is supported by the fact the application notes of the SAW GC vendor (Appendix D) show method detection limits for most analytes well within the concentration range of sample TX-113. For example, this sample has a carbontetrachloride concentration of 290 ppbv. The vendor determined the Estimated Detection Limit for this compound is $70 \mathrm{ppbv}$. The experiment with the water-saturated air sample showed water quickly saturates the SAW detector. The water then degrades the resolution of other peaks when it desorbes from the detector crystal over time. The vendor has used the instrument for the analysis of VOC in groundwater samples. They used a water trap at the SAW GC inlet to avoid interference. However, the analytes were restricted to nonpolar compounds such as chlorinated compounds and aromatics. This procedure cannot be used with Hanford tanks because many of the most common analytes in these samples are polar compounds such as 1-butanol. 
HNF-1861 Rev. 0

Table 10: Permanent Gas Composition of Tank TX-113

\begin{tabular}{|l|l|}
\hline Compound & Concentration (ppmv) \\
\hline $\mathrm{H}_{2}$ & $<27$ \\
\hline $\mathrm{CO}_{2}$ & 450 \\
\hline $\mathrm{N}_{2} \mathrm{O}$ & $<16$ \\
\hline $\mathrm{CO}$ & $<32$ \\
\hline $\mathrm{CH}_{4}$ & $<38$ \\
\hline Non-methane Total Organic Carbon & 1.5 \\
\hline $\mathrm{NO}$ & 4.1 \\
\hline $\mathrm{NO}_{2}$ & 2.7 \\
\hline Water & 14,000 \\
\hline Ammonia & 22 \\
\hline
\end{tabular}


HNF-1861 Rev. 0

\subsection{CONCLUSIONS}

Evaluation of the SAW GC for the screening of Hanford tank headspace samples was done in 3 stages: Calibration for 11 compounds typical of Hanford tank samples, determination of the instrument performance with a certified 6 component standard gas mixture, and testing of the SAW GC with 7 vapor samples collected from Hanford waste tanks.

The instrument calibration provided good linearity for 8 of the compounds in the range of approximately 10 to $150 \mathrm{ppmv}$. Below this range ( 1 to $10 \mathrm{ppmv}$ ) and above (to $300 \mathrm{ppbv}$ ) the calibration curve was not linear and had a different slope. Calibration was not possible under the vendor recommended conditions for the remaining 4 compounds because they were either very volatile and coeluted with water at the beginning of the analysis, or, they were not volatile enough to elute from the column. It was found that 1 ppmv could reliably be detected.

Analysis of a 6 component certified gas standard showed the instrument was able to detect and quantitate all 3 compounds for which calibration data were available. Precision was quite good for the analytes with a \% RSD of better than $21 \%$. Accuracy varied considerably between the compounds; for 2 analytes the $\%$ RPD was $<40 \%$ and for the third compound it was $209 \%$.

The 7 tank samples were analyzed previously by another technique (TO-14). These data showed the tank headspace samples had concentrations of volatile organic compounds in the low ppbv range ( 5 to $35 \mathrm{ppbv}$ except for one sample which had 6 compounds in the range from 6 to 680 ppbv). The SAW GC analyses did not detect any analytes.

The SAW GC allows for very fast analysis times, generally less than 30 seconds for a complete analysis. However, this speed affects the resolution of components and analyses are best limited to VOC mixtures with about 5 major compounds or less. Although the SAW detector is an universal detector, in the VOC screening mode it is best used for compounds with boiling points in the range of approximately 40 to $150^{\circ} \mathrm{C}$. The instrument needs an operator with a good understanding of instrumental analysis techniques to produce useful data. The operating conditions used in these experiments were recommended by the vendor and no special attempt was made to optimize the instrument parameters. From our experience and discussions with the EST personnel, it is likely the SAW GC performance could be improved for a specific set of samples and conditions. However, we decided to use a "generic" set of operating conditions because the Hanford tank samples are highly variable in their composition.

Although the SAW GC is not an ideal tool for screening tank headspace vapors, the instrument has some unique properties making it useful in other circumstances. The high speed of the analyses make it a good screening tool for selected compounds in a relatively dry environment. This includes the screening of ambient air or soil samples for higher concentrations ( $>1 \mathrm{ppmv}$ ) of nonpolar compounds, such as chlorinated and aromatic compounds. The SAW GC in a slightly 


\section{HNF-1861 Rev, 0}

different configuration has also been shown in other studies to be a good screening tool for semivolatile compounds, such as PCB's and dioxins. It is recommended to investigate using the SAW GC at the Hanford Site for these applications. 
HNF-1861 Rev. 0

\section{ACKNOWLEDGEMENT}

We would like to acknowledge the support of Electronic Sensor Technology, Westlake Village, $\mathrm{CA}$, for providing two SAW GC instruments on loan. We are especially indebted to Dave McGuire from EST for helping with the setup of the instruments and providing support. 
HNF-1861 Rev. 0

APPENDIX A

CALIBRATION CURVES OF ANALYTE CHEMICALS 
HNF-1861 Rev. 0

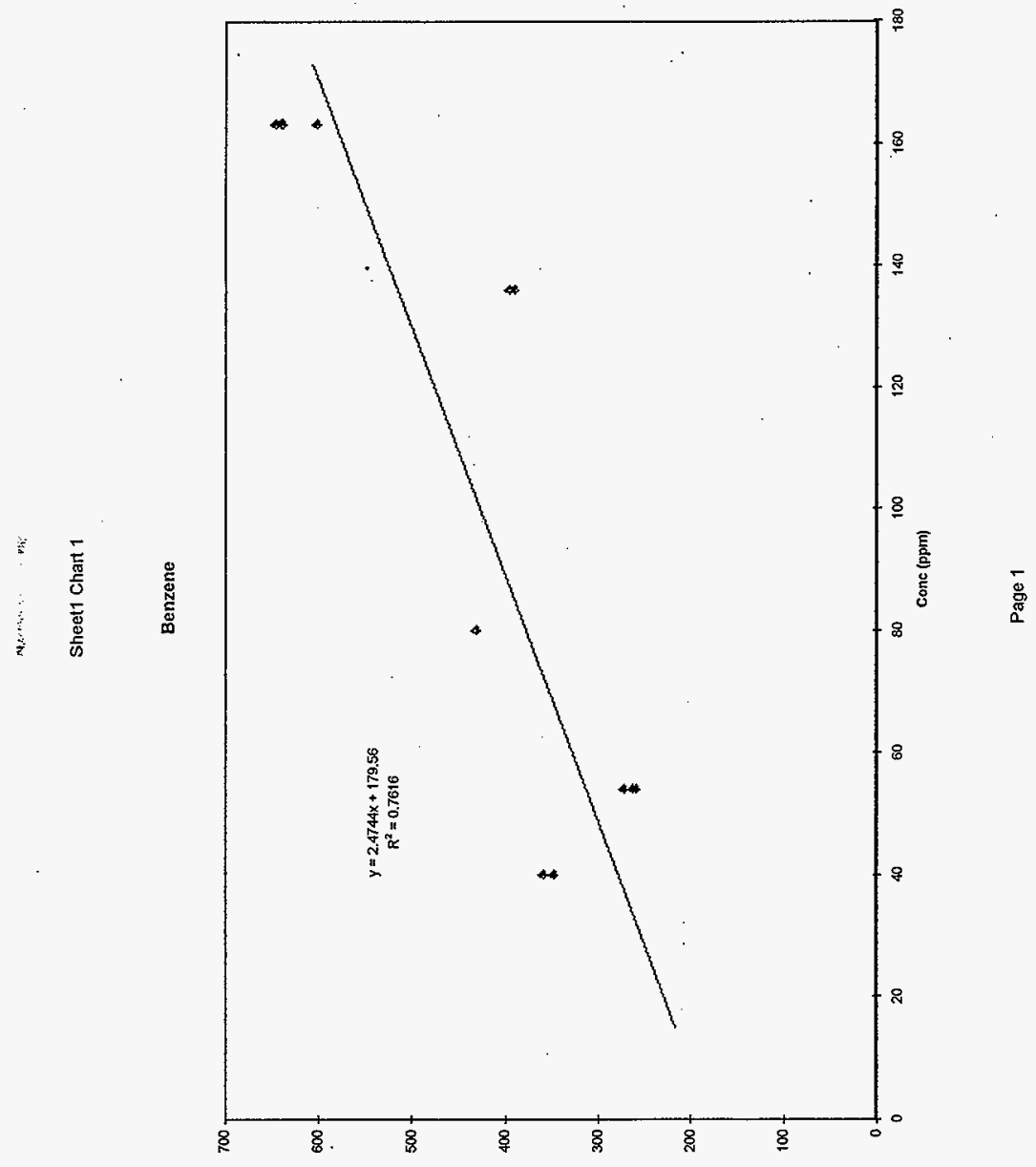


HNF-1861 Rev. 0

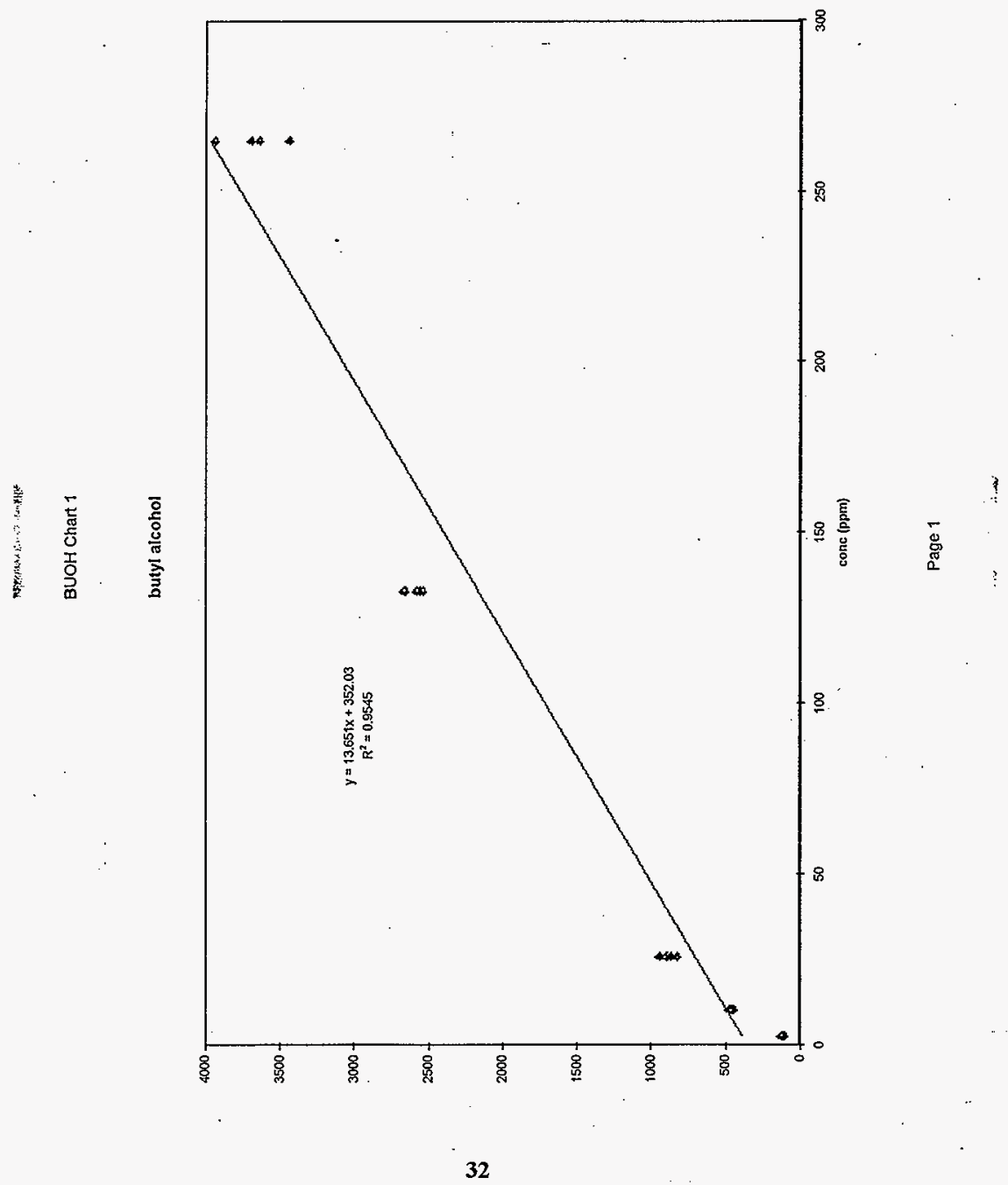




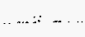

HNF-1861 Rev. 0

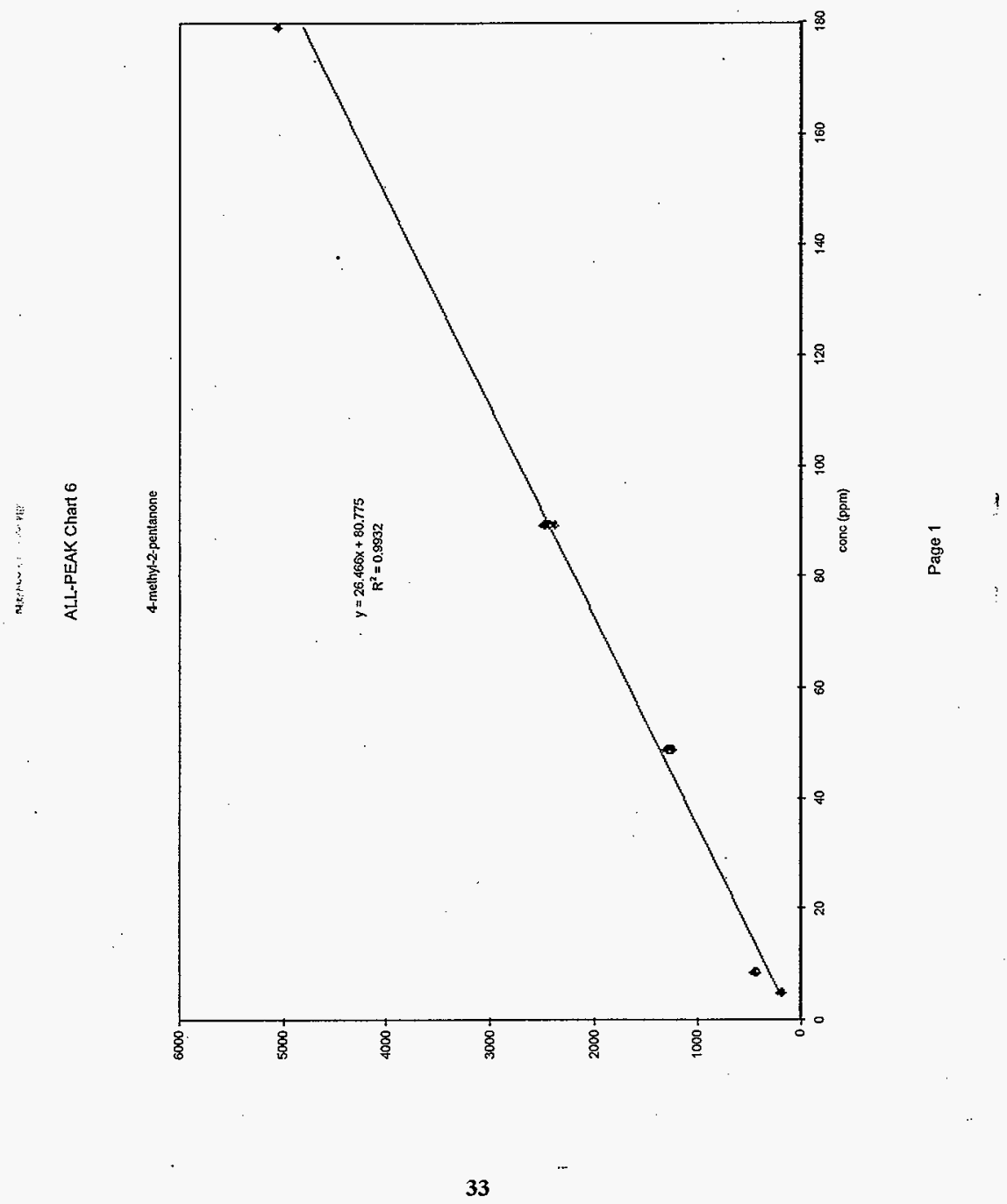


HNF-1861 Rev. 0

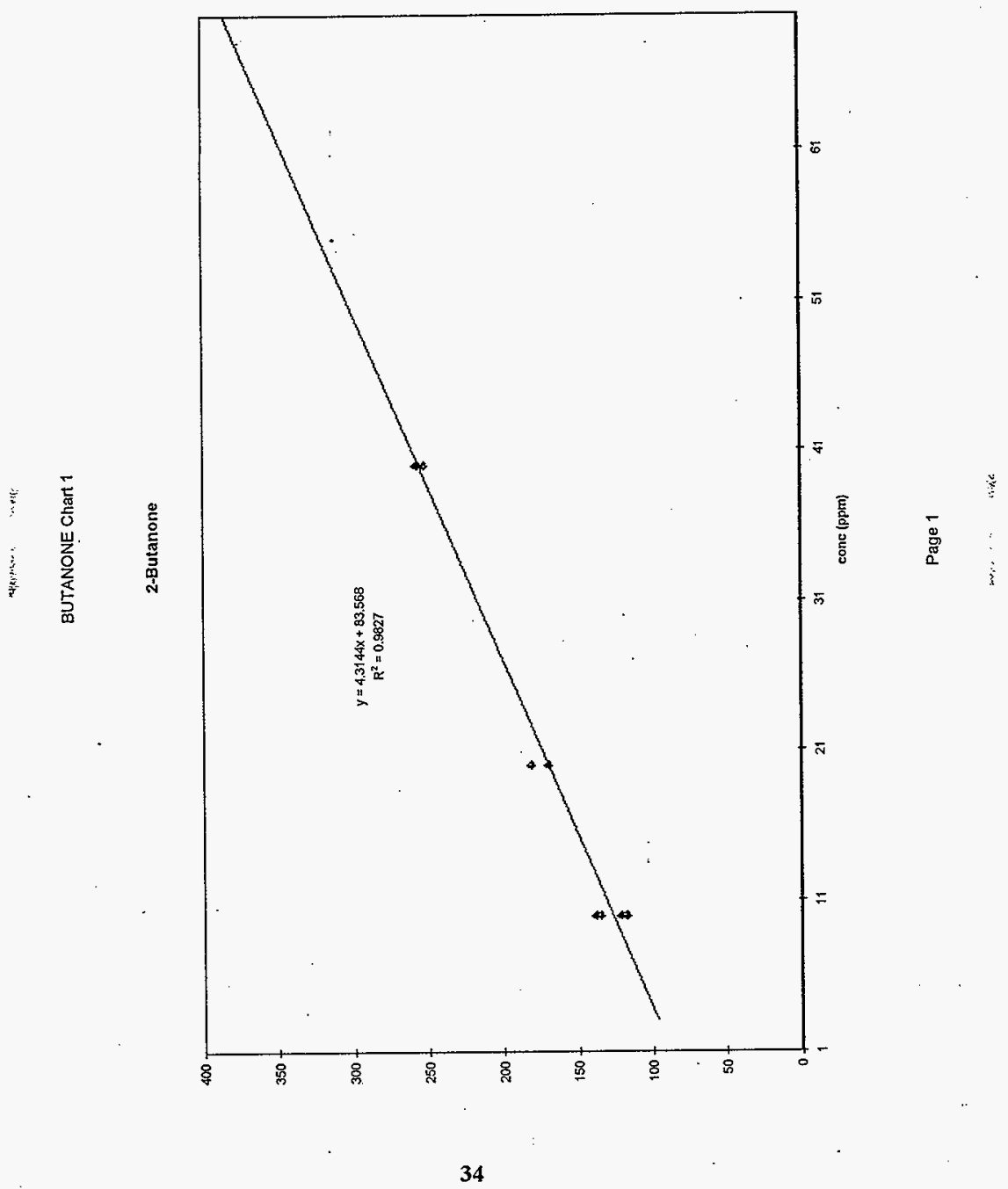


HNF-1861 Rev. 0

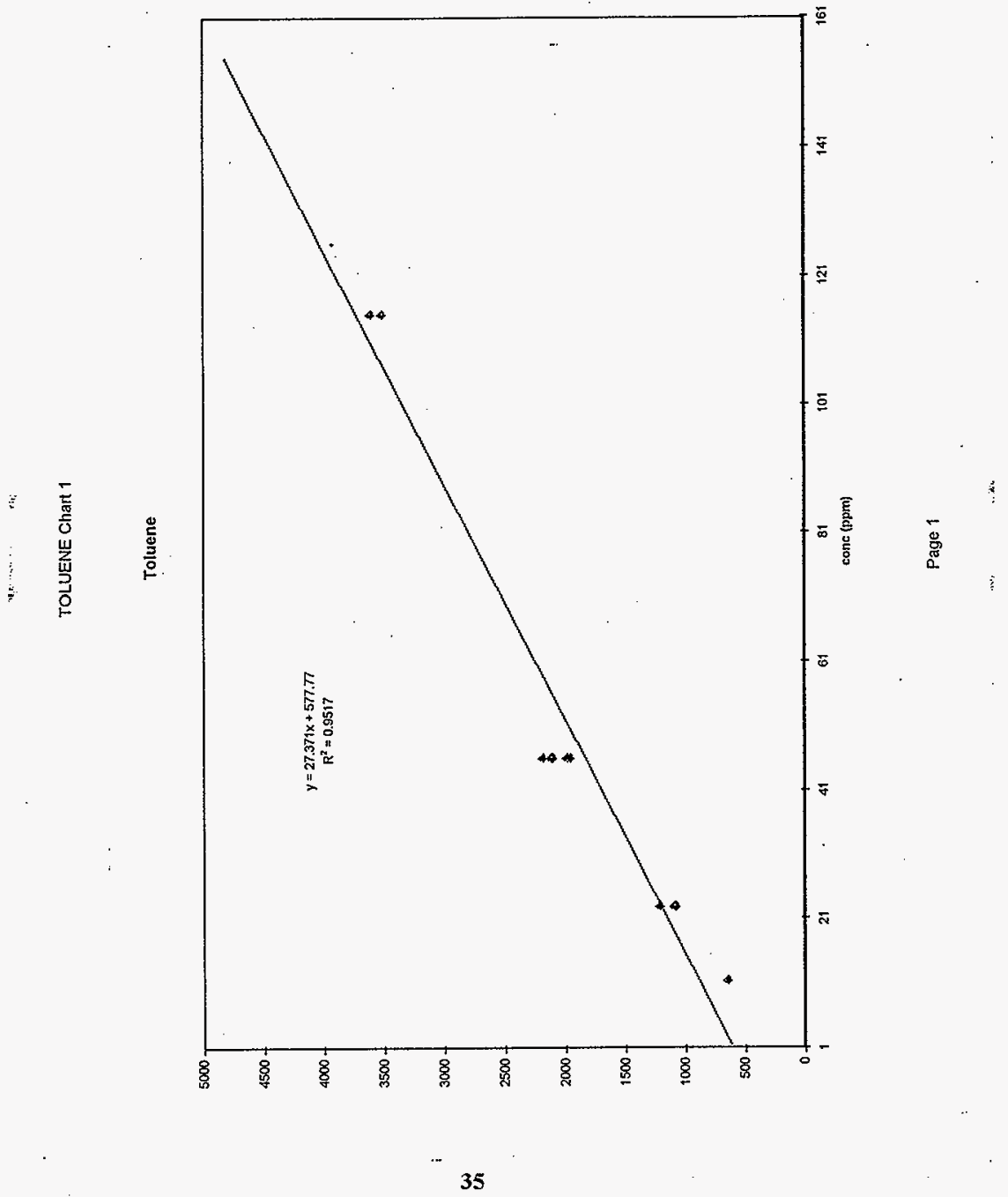


HNF-1861 Rev. 0

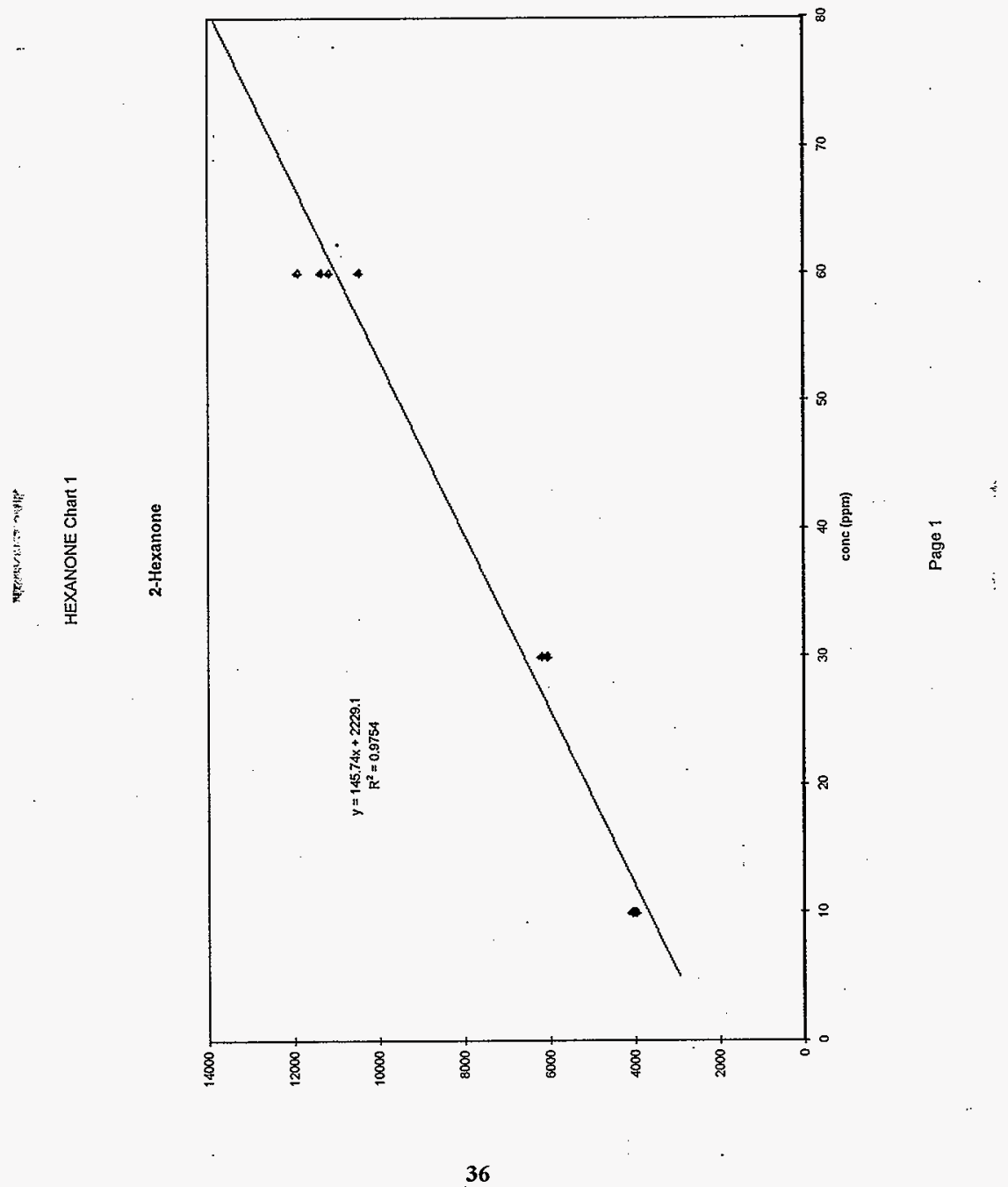


HNF-1861 Rev, 0

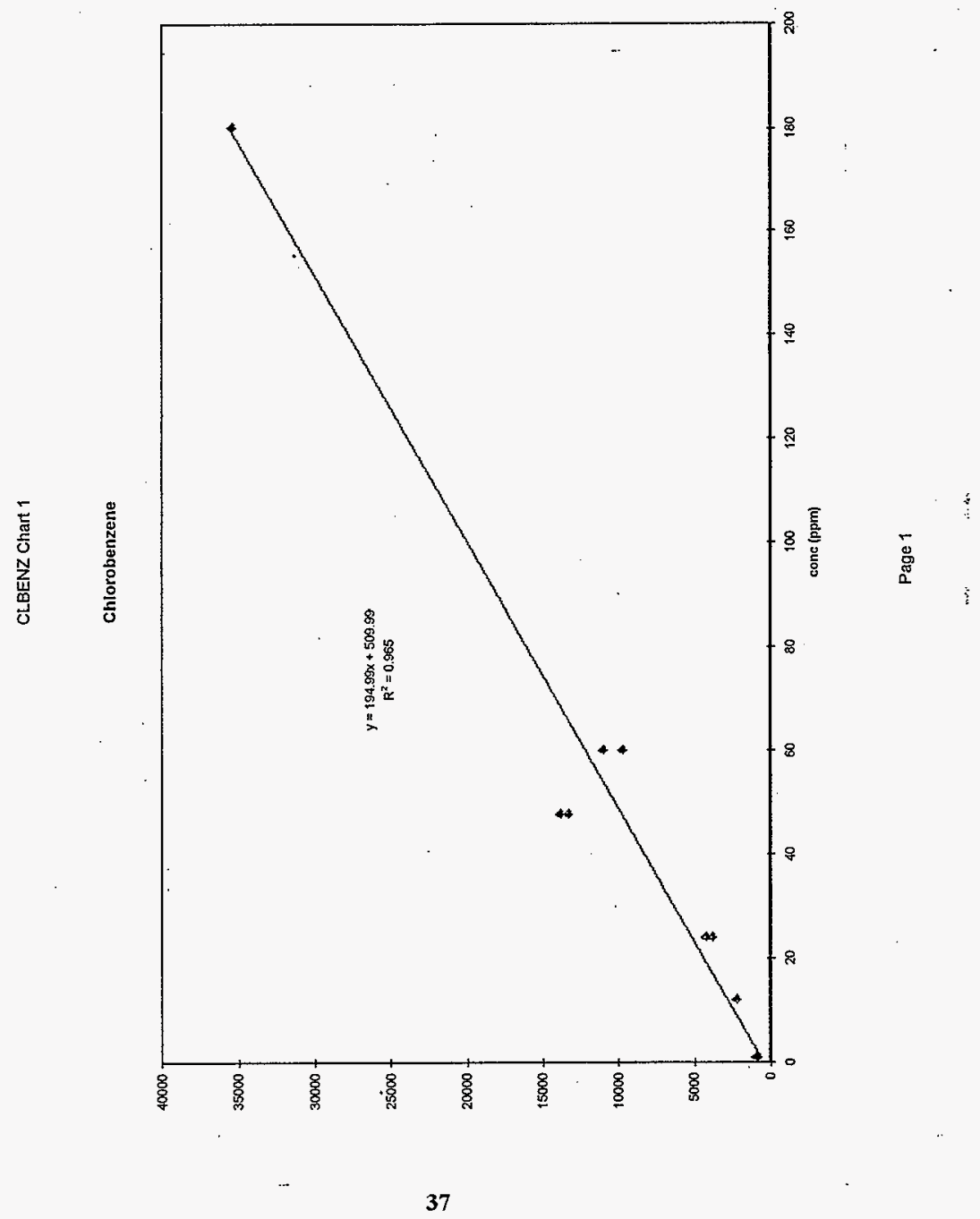


HNF-1861 Rev:0

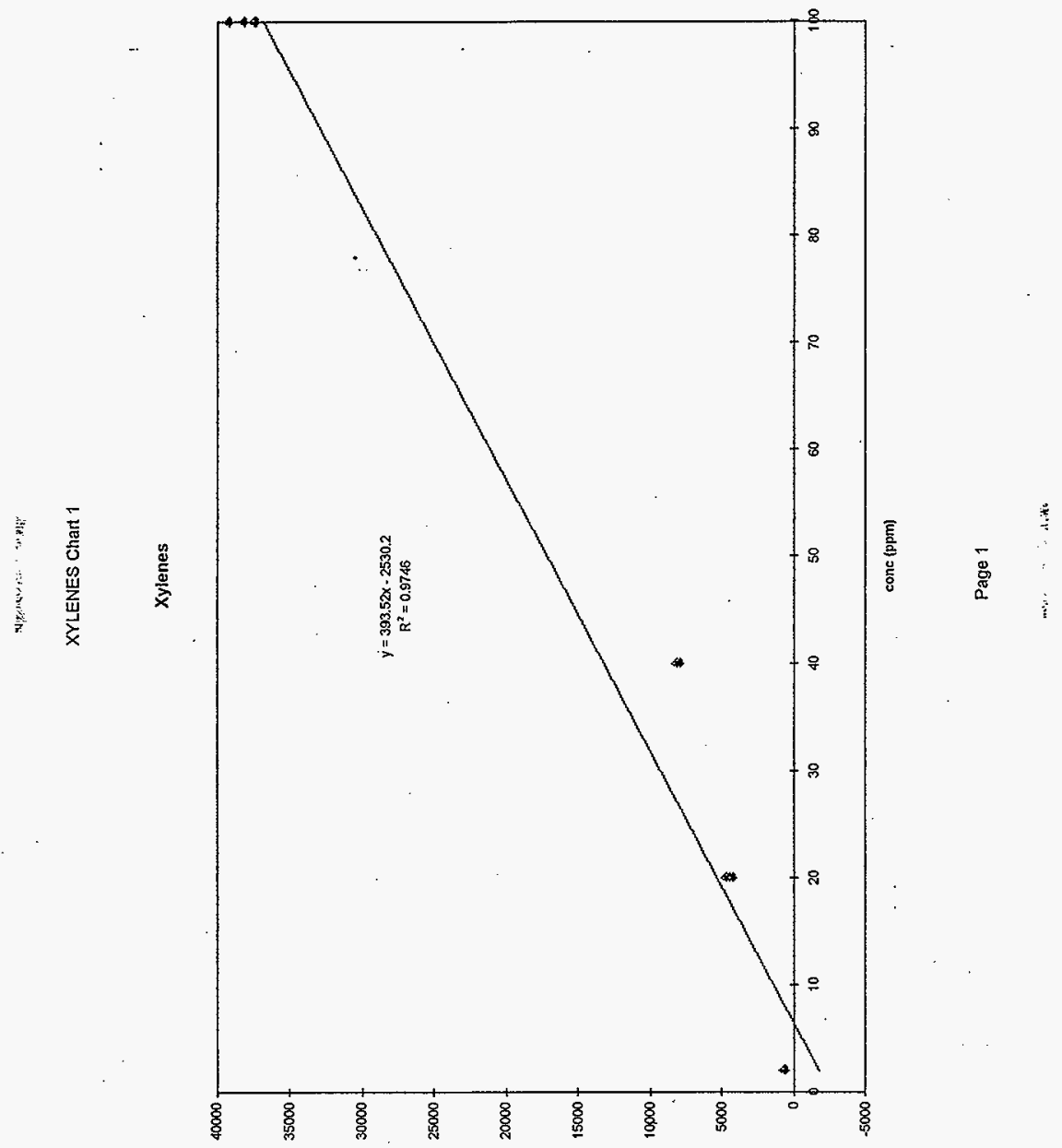


HNF-1861 Rev. 0

APPENDIX B

ANALYSES/CHROMATOGRAMS OF NIST GAS STANDARD 


\section{HNF-1861 Rev. 0}

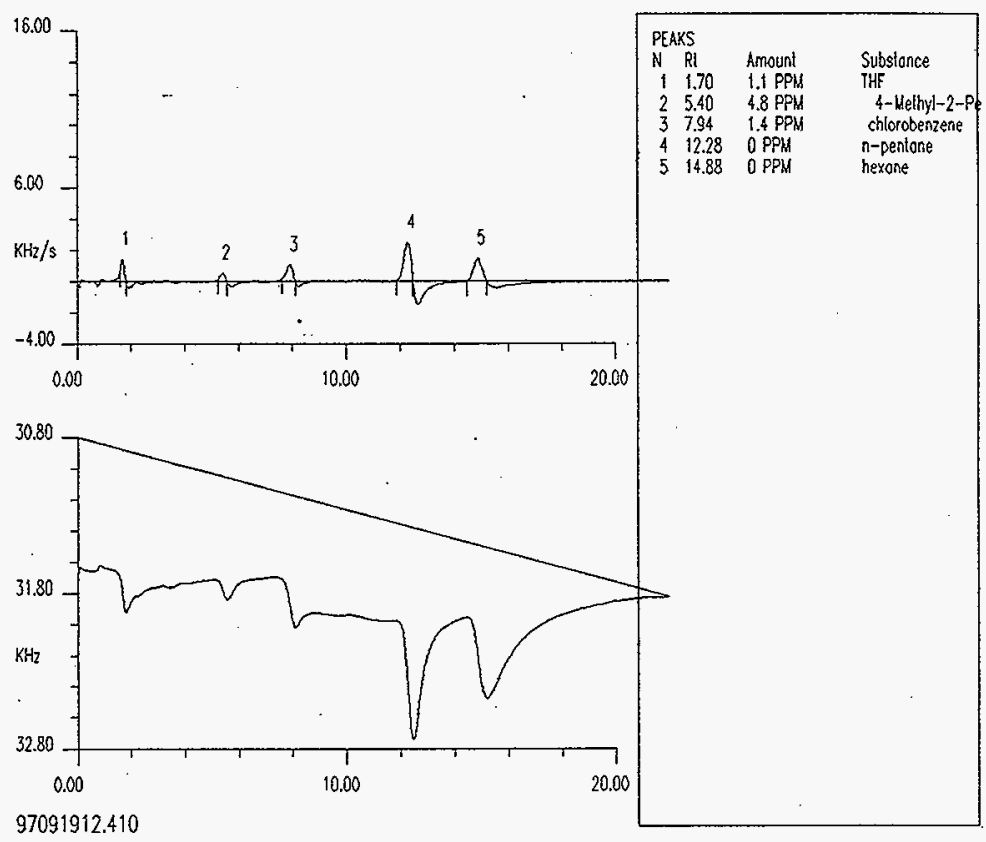

Notes

NIST Stondurd botlle somple

No woter trop

15 sec somple time

$3 \mathrm{deg} / \mathrm{sec} 1085 \mathrm{deg}$

Sow 139

$15 / 40 / 70 / 80$

column 08-624

Somple: see logbook WHC-N-1375, 5

$\begin{array}{ll}\text { Fite: } & 97091912.410 \\ \text { Jime: } & 12: 41: 05 \\ \text { Dole: } & \text { 19-Sep-97 } \\ \text { Method: } & \text { iwrs1,mlh } \\ \text { Peok: } & \text { iwrsi.pkd }\end{array}$

$\begin{array}{ll}\text { Pump Time: } & 15 . \\ \text { Dola Role: } & 20 \mathrm{~ms} / \text { point } \\ \text { Averoge: } & 1 \\ \text { Smath: } & 6 \\ \text { Peok Smooth: } & 2 \\ \text { Peak Ihreshold: } & 1000 \\ \text { Peok Minimum: } & 50\end{array}$

Peok Minimum:
Sow Temp: $\quad 15.0$

Column Temp: $\quad 40.2$

Inlel Temp: $\quad 80.2$

Volve Temp: $\quad 70.5$

Trop Volloge: $\quad 59.8$

Sow Number 205.

VCO Frequency. $\quad 500.180 \mathrm{kHiz}$ 


\section{ANF-1861 Rev. 0}

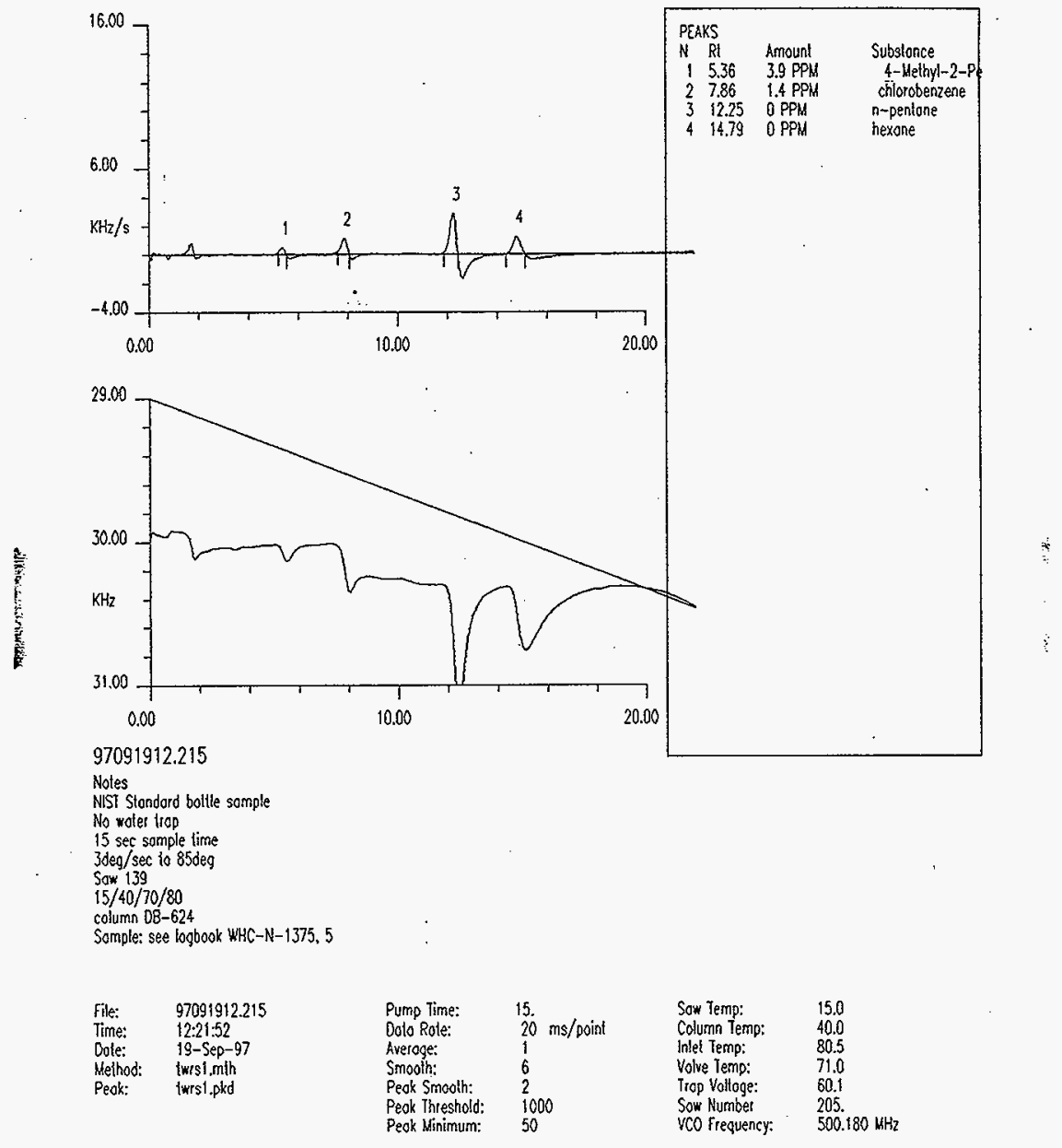




\section{HNF-1861 Rev. 0}

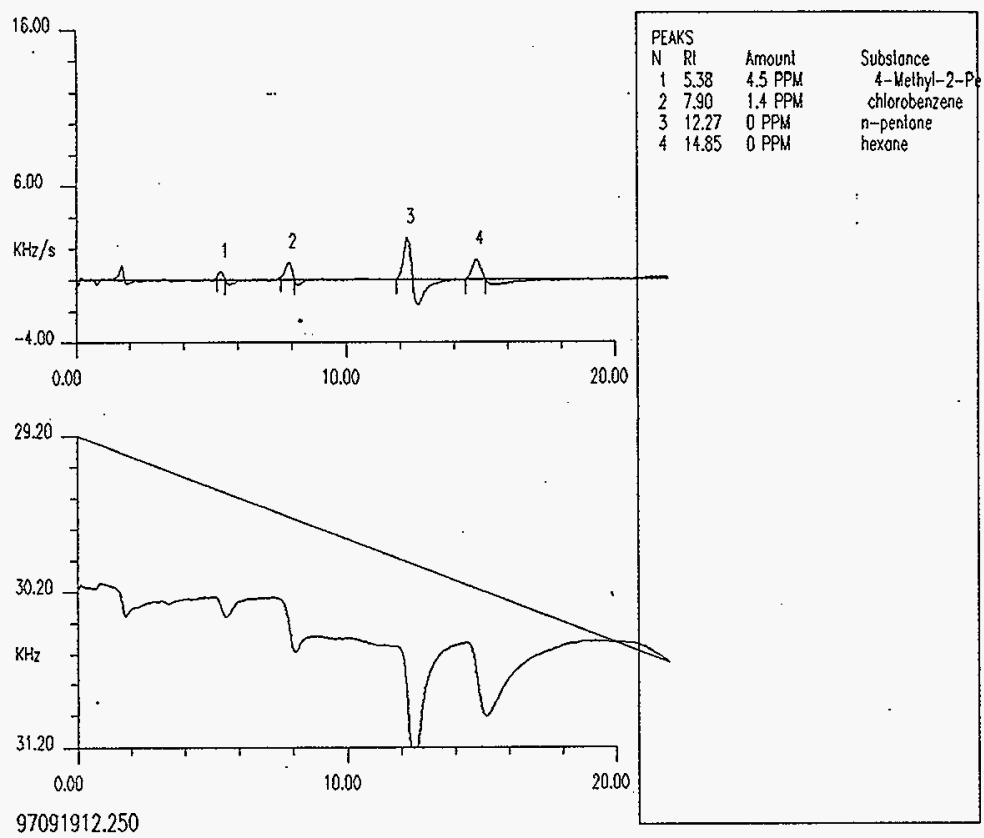

Notes

NiST Stondord boille sample

No woter trop

15 sec somple time

$3 \mathrm{deg} / \mathrm{sec} 1085 \mathrm{deg}$

Sow 139

$15 / 40 / 70 / 80$

column DB-624

Somple: see logbook WHC-N-1375, 5

$\begin{array}{ll}\text { File: } & \text { 97091912.250 } \\ \text { Time: } & \text { 12:25:05 } \\ \text { Cole: } & 19-\text { Sep-97 } \\ \text { Weihod: } & \text { \{wrsi.mth } \\ \text { Peox: } & \text { twrsl.pkd }\end{array}$

$\begin{array}{ll}\text { Pump Time: } & 15 . \\ \text { Dolo Role: } & 20 \mathrm{~ms} / \text { point } \\ \text { Averoge: } & 1 \\ \text { Smooth: } & 6 \\ \text { Peok Smooth: } & 2 \\ \text { Peok Threshold: } & 1000 \\ \text { Peok Uinimum: } & 50\end{array}$

Sow Temp: $\quad 15.0$

Column Temp: $\quad 40.1$

Inlet Temp: $\quad 80.5$

Volve Temp: $\quad 71.0$

Irop Voltoge: $\quad 59.8$

Sow Number 205

vCO Frequency: $\quad 500.180 \mathrm{MHz}$ 


\section{HNF-1861 Rev. 0}

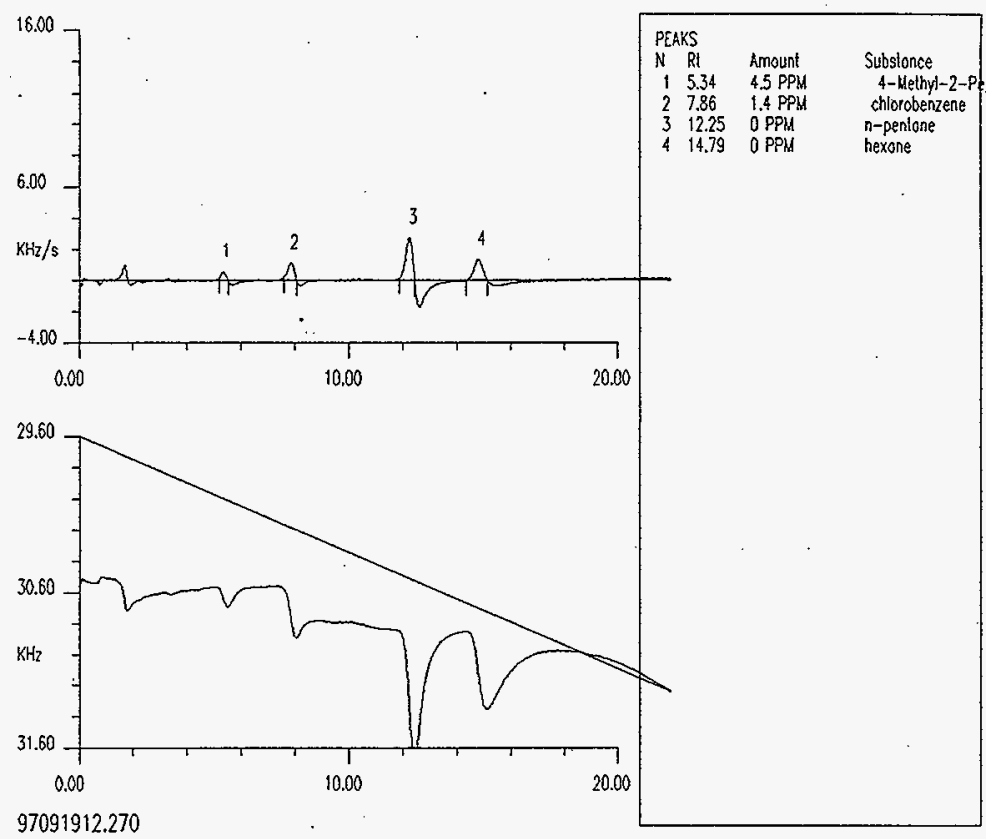

Notes

NISI Standord ballie somple

No woter irop

15 sec samole time

$3 \mathrm{deg} / \mathrm{sec} 1085 \mathrm{deg}$

Sow 139

$15 / 40 / 70 / 80$

column 0B-624

Somple: see logbook WHC-N-1375, 5

$\begin{array}{ll}\text { Fite: } & 97091912.270 \\ \text { Time: } & 12+27: 05 \\ \text { Dote: } & \text { 19-Sep-97 } \\ \text { Helhod: } & \text { twrsl.mth } \\ \text { Peok: } & \text { iwrsl.pkd }\end{array}$

$\begin{array}{ll}\text { Pump Time: } & 15 . \\ \text { Dolo Role: } & 20 \mathrm{~ms} / \text { point } \\ \text { Averoge: } & 1 \\ \text { Smoth: } & 6 \\ \text { Peok Smoolh: } & 2 \\ \text { Peok Threshold: } & 1000 \\ \text { Peok Hinimum: } & 50\end{array}$

Peok Minimum:
PEAKS

1 Rt Amount

$1534 \quad 45 \mathrm{PPM}$

$7.86 \quad 1.4 \mathrm{PPI}$

$3 \quad 12.25 \quad 0 \mathrm{PPM}$

414.79 OPPM

Substonce

4-Wethy-2-Pe.

i-penlane

hexone

$\begin{array}{ll}\text { Nethod: } & \text { twrsl.mth } \\ \text { Peok: } & \text { iwrsi.pkd }\end{array}$

$\begin{array}{ll}\text { Sow Temp: } & 15.0 \\ \text { Column Temp: } & 40.1 . \\ \text { Inlei Temp: } & 80.5 \\ \text { Volve Tenn: } & 70.8 \\ \text { Irop Voltoge: } & 59.9 \\ \text { Sow Humber } & 205 . \\ \text { vco Frequency: } & 500.180 \mathrm{WHz}\end{array}$




\section{HNF-1861 Rev. 0}

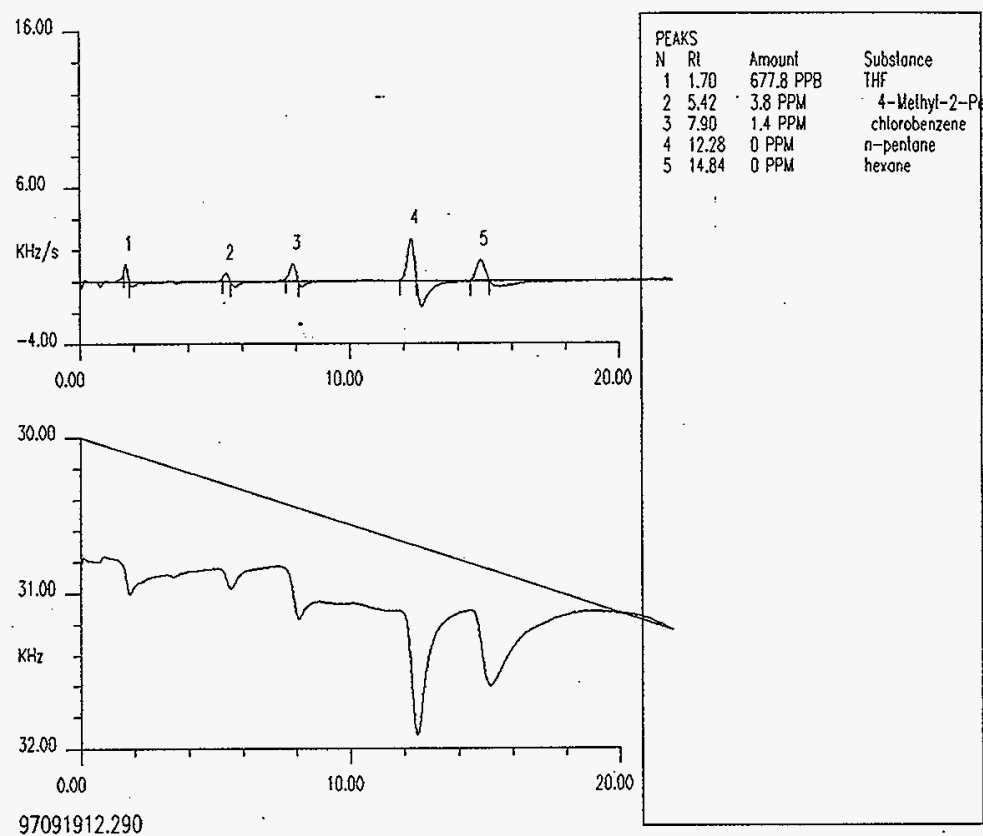

Notes

NIST Stondard botile sample

No woler trop

15 sec somple time

$3 \mathrm{deg} / \mathrm{sec}$ is $85 \mathrm{deg}$

Sow 139

$15 / 40 / 70 / 80$

columin 08-624

Somple: see logbook wHC-N-1375, 5

$\begin{array}{ll}\text { File: } & 97091912.290 \\ \text { Time: } & 12: 29: 05 \\ \text { Daie: } & 19-\operatorname{Sep}-97 \\ \text { Melhod: } & \text { twrs1.mth } \\ \text { Peok: } & \text { twrsi.pkd }\end{array}$

Pump Time:

Doto Role:

Averoge:

Smooth:

Peok Smooth:

Peok Thieshold:

Peck Minimum:

15.
$20 \mathrm{~ms} /$ Doint
1
6
2
1000
50

Sow Temp: $\quad 15.0$

Column Temo: $\quad 40.2$

Inlet Temp: $\quad 80.3$

Volve Temp: $\quad 70.8$

Irop Voltoge: $\quad 80.2$

Saw Number $\quad 205$.

VCO Frequency. $\quad 500.180 \mathrm{kHz}$ 
HNF-1861 Rev. 0

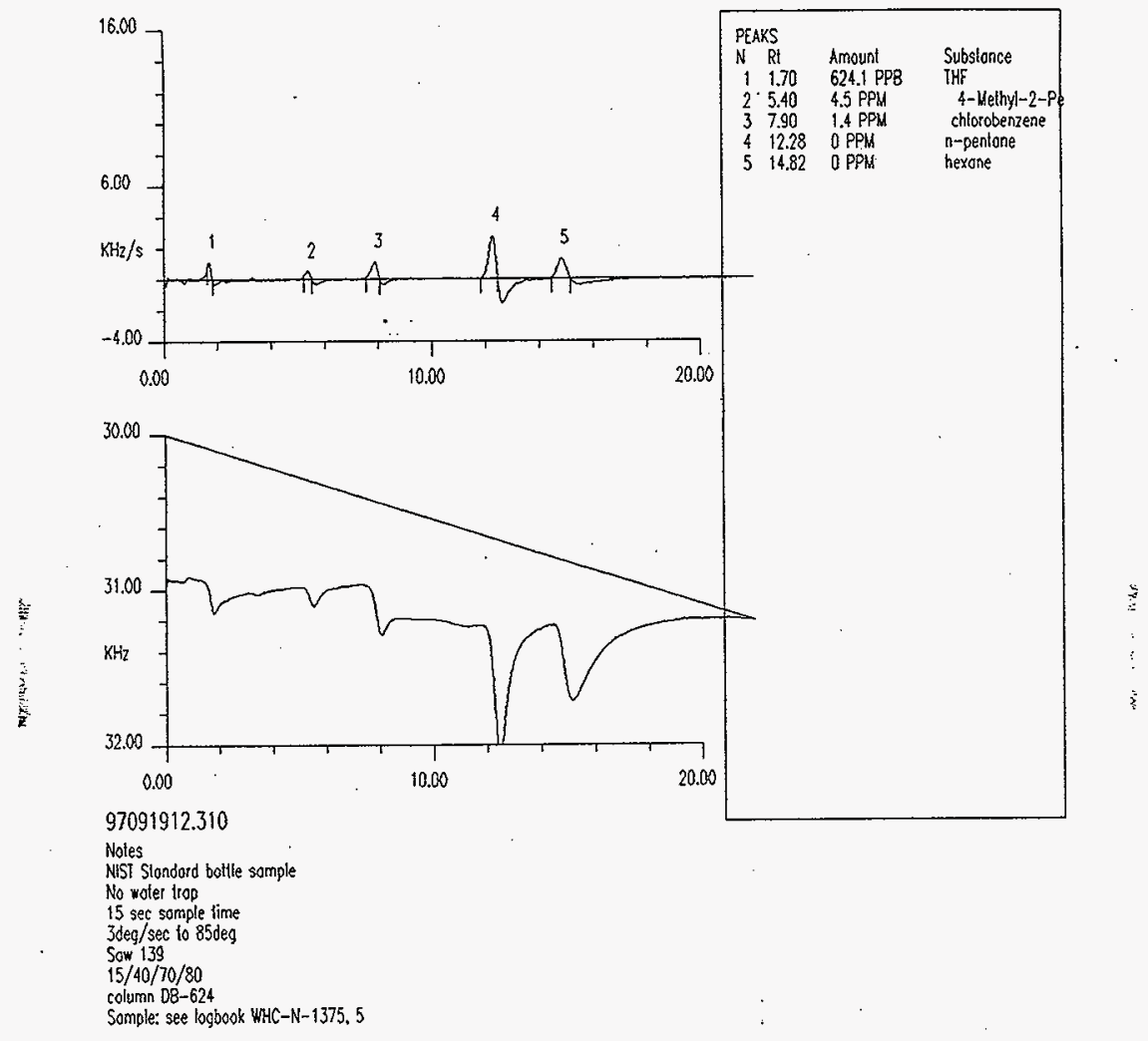

$\begin{array}{llll}\text { Pump Time: } & 15 . & \text { Sow Temp: } & 15.0 \\ \text { Dolo Role: } & 20 \mathrm{~ms} / \text { point } & \text { Column Temp: } & 40.1 \\ \text { Average: } & 1 & \text { Intet Temp: } & 80.3 \\ \text { Smosth: } & 6 & \text { Valve Temp: } & 70.9 \\ \text { Peok Smooth: } & 2 & \text { Trop Voitoge: } & 60.0 \\ \text { Peok Threshold: } & 1000 & \text { Sow Number } & 205 . \\ \text { Peok Mirimum: } & 50 & \text { VCo Frequency: } & 500.180 \mathrm{WHz}\end{array}$


HNF-1861 Rev. 0

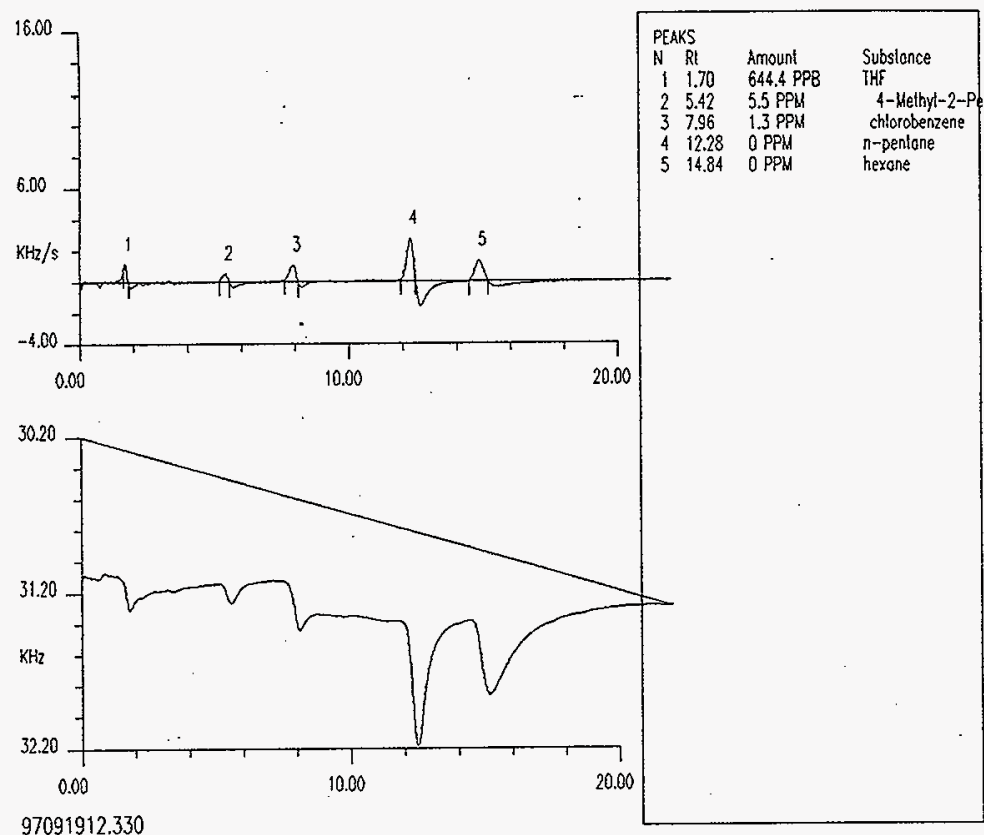

Notes

NISI Stondord bolile sample

No water trop

$15 \mathrm{sec}$ somple time

$3 \mathrm{deg} / \mathrm{sec}$ 10 $85 \mathrm{deg}$

Sow 139

$15 / 40 / 70 / 80$

column .OB-624

Sample: see logbook WHC-N-1375, 5

$\begin{array}{ll}\text { File: } & 97091912.330 \\ \text { Time: } & 12: 33: 05 \\ \text { Dole: } & \text { 19-Sep-97 } \\ \text { Method: } & \text { iwrst.mith } \\ \text { Peok: } & \text { iwrs1.pkd }\end{array}$

$\begin{array}{ll}\text { Pump Time: } & 15 . \\ \text { Dolo Role: } & 20 \mathrm{~ms} / \text { point } \\ \text { Averoge: } & 1 \\ \text { Smooth: } & 6 \\ \text { Peok Smooth: } & 2 \\ \text { Peok Threshold: } & 1000 \\ \text { Peok Uinimum: } & 50\end{array}$

Sow Temp: $\quad 15.0$

Column Temp: $\quad 40.1$

Inlet Temp: $\quad 80.3$

Volve Temp: $\quad 70.6$

Trop Voltage: $\quad 59.9$

Sow Number 205

VCO Frequency: $\quad 500.180 \mathrm{KH}$ 


\section{HNF-1861 Rev. 0}

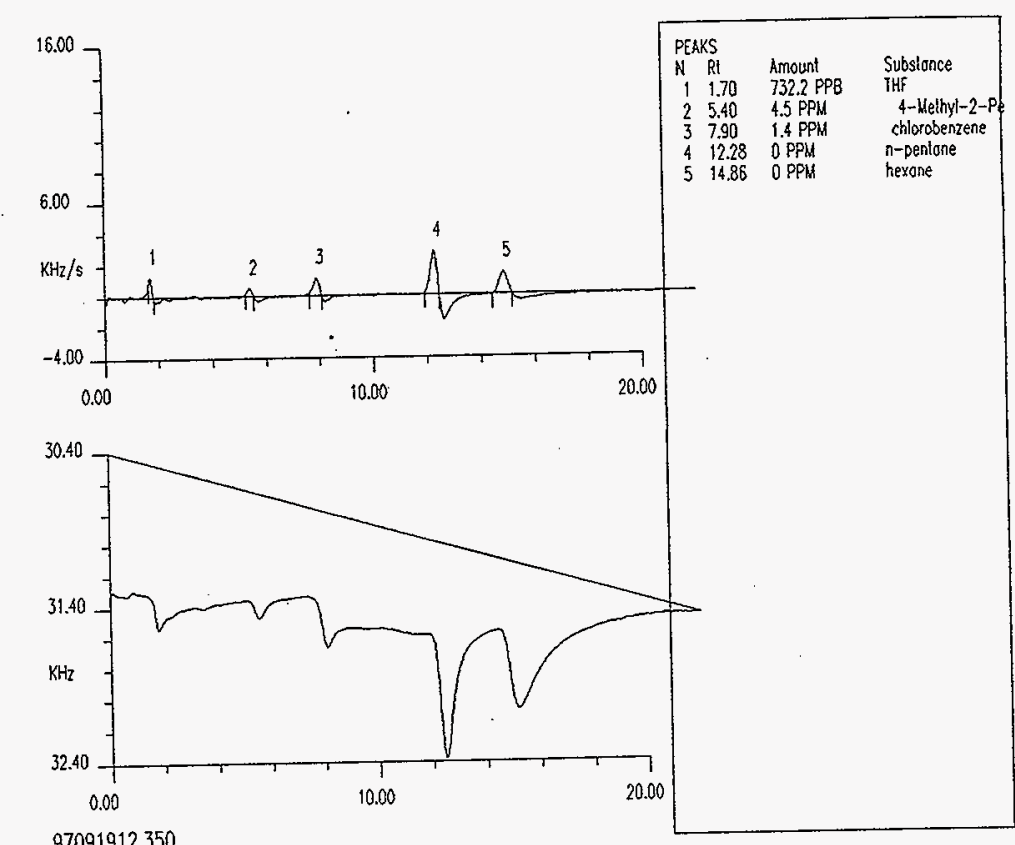

97091912.350

Notes

NIST Standord botlle somple

No woter Irop

15 sec somple time

$3 \mathrm{deg} / \mathrm{sec} 1085 \mathrm{deg}$

Sow 139

$15 / 40 / 70 / 80$

column 08-624

Somple: see logbook wHC-N-1375. 5

$\begin{array}{ll}\text { File: } & 97091912.350 \\ \text { Time: } & 12: 35: 05 \\ \text { Oole: } & \text { 19-Sep-97 } \\ \text { Meihod: } & \text { iwrs1.mih } \\ \text { Peok: } & \text { iwrs1.pkd }\end{array}$

$\begin{array}{ll}\text { Pump Time: } & 15: \\ \text { Dolo Role: } & 20 \mathrm{~ms} / \text { point } \\ \text { Averoge: } & 1 \\ \text { Smooth: } & 6 \\ \text { Peak Smoalh: } & 2 \\ \text { Peok Threshold: } & 1000 \\ \text { Peak Hinimum: } & 50\end{array}$

$\begin{array}{ll}\text { Sow Temp: } & 15.0 \\ \text { Column Temp: } & 40.2 \\ \text { Inlet Temp: } & 80.3 \\ \text { Volve Temp: } & 70.6 \\ \text { Trop Voitoge: } & 60.0 \\ \text { Sow Number } & 205 . \\ \text { VCO Frequency: } & 500.180 \mathrm{HHz}\end{array}$




\section{HNF-1861 Rev. 0}

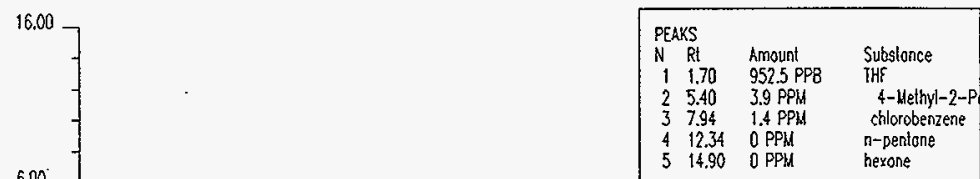

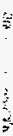
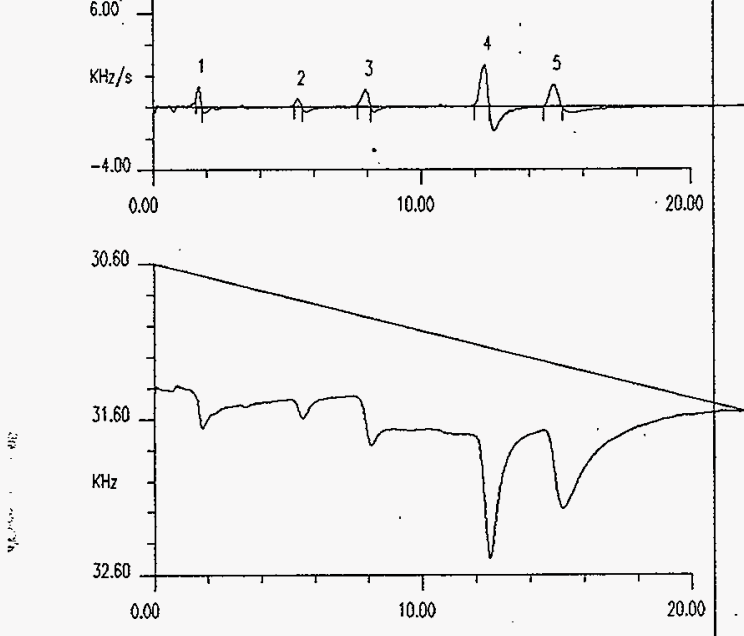

97091912.370

Noles

NIST Slondord boille sample

No zoler trop

$15 \mathrm{sec}$ somple time

$3 \mathrm{deg} / \mathrm{sec}$ io $85 \mathrm{deg}$

Saw 139

$15 / 40 / 70 / 80$

column DB-624

Somple: see logbook

$\begin{array}{ll}\text { Fike: } & 97091912.370 \\ \text { Time: } & 12: 37: 05 \\ \text { Dote: } & \text { 19-Sep-97 } \\ \text { Wethod: } & \text { twrsi.mih } \\ \text { Peok: } & \text { iwrsi.pkd }\end{array}$

$\begin{array}{llll}\text { Pump Time: } & 15 . & \text { Sow Temp: } & 15.0 \\ \text { Doio Role: } & 20 \mathrm{~ms} / \text { point } & \text { Column Temp: } & 40.2 \\ \text { Averoge: } & 1 & \text { Inlel Temp: } & 80.3 \\ \text { Smoolh: } & 6 & \text { Yolve Temp: } & 70.6 \\ \text { Peok Smooth: } & 2 & \text { Trop Volloge: } & 60.3 \\ \text { Peak Threshold: } & 1000 & \text { Sow Number } & 205 . \\ \text { Peok Kinimum: } & 50 & \text { VCO Frequency: } & 500.180 \mathrm{MHz}\end{array}$




\section{HNF-1861 Rev. 0}

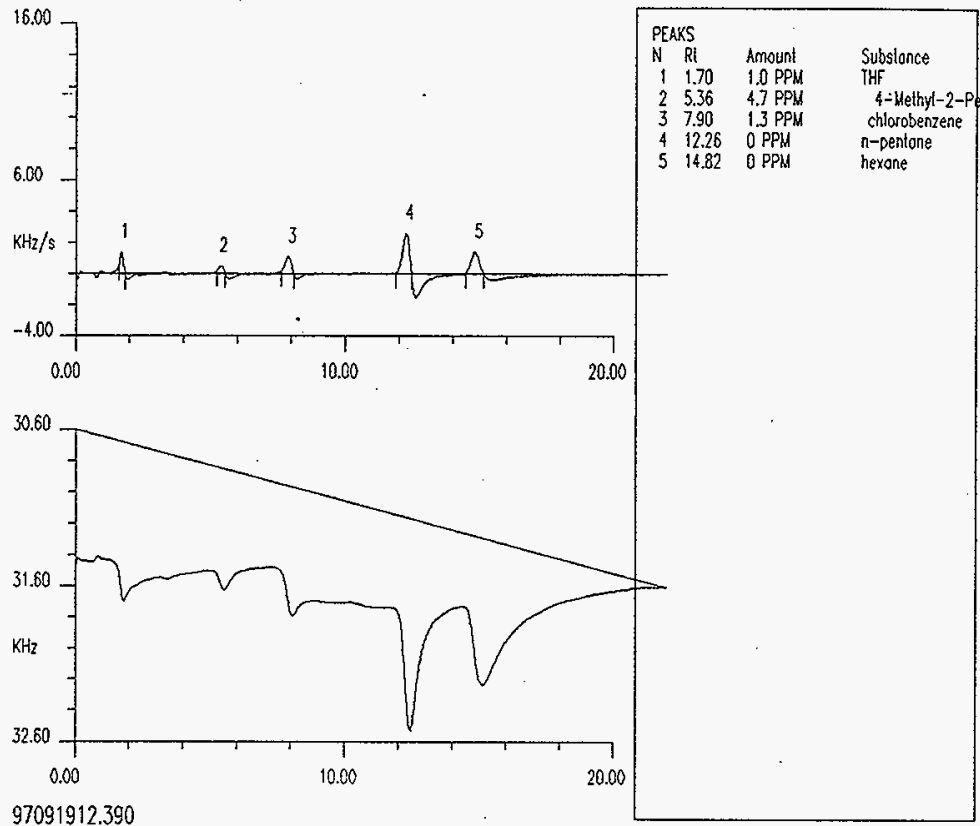

\section{Notes}

NIST Stondord bollle somple

No walet trop

$15 \mathrm{sec}$ somple time

$3 \mathrm{deg} / \mathrm{sec}$ to $85 \mathrm{deg}$

Sow 139

$15 / 40 / 70 / 80$

column DB-624

Sample: see logbook WHC-N-1375, 5

$\begin{array}{ll}\text { File: } & 97091912.390 \\ \text { Time: } & 12: 39: 05 \\ \text { Dole: } & \text { 19-Sep-97 } \\ \text { Method: } & \text { iwrsl.milh } \\ \text { Peok: } & \text { fwrst.pkd }\end{array}$

Pump Time: $\quad 15$ Dolo Role:

Averoge:

Srnooth:

Peok Smooth:

Peok Threshold:

Peok Winimum:
15.

$20 \mathrm{~ms} /$ point

6

100

50

$\begin{array}{ll}\text { Sow Temp: } & 15.0 \\ \text { Column Temp: } & 40.2 \\ \text { Inlel Temp: } & 80.2 \\ \text { Volve Temp: } & 70.5 \\ \text { Trop Volioge: } & 60.1 \\ \text { Sow Number } & 205 . \\ \text { Vo Fiequency: } & 500.180 \mathrm{MHz}\end{array}$


HNF-1861 Rev. 0

APPENDIX C

ANALYSES/CHROMATOGRAMS OF WASTE TANK SAMPLES 


\section{HNF-1861 Rev, 0}

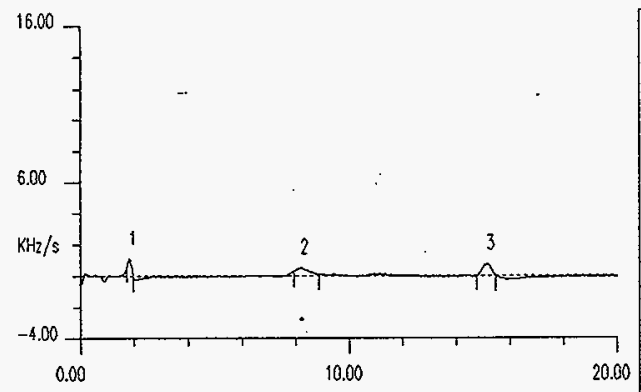

97091913.111

Notes

V7019-A05-077

Wosle Tonk SX-107

No voter trop

$30 \mathrm{sec}$ somple lime $27 \mathrm{cc} / \mathrm{min}$

$3 \mathrm{deg} / \mathrm{sec}$ to $85 \mathrm{deg}$

Saw 139

$15 / 40 / 70 / 80$

column 08-624

Somple: see logbook WHC-N-1375, 5

$\begin{array}{ll}\text { File: } & 97091913.111 \\ \text { Time: } & 13: 11: 18 \\ \text { Dote: } & 19-5 e p-97 \\ \text { Method: } & \text { iwrsl.milh } \\ \text { Peok: } & \text { twrsi.pkd }\end{array}$

$\begin{array}{ll}\text { Pump Time: } & 30 . \\ \text { Dolo Role: } & 20 \mathrm{~ms} / \text { point } \\ \text { Averoge: } & 1 \\ \text { Smoolh: } & 6 \\ \text { Peok Smoolh: } & 2 \\ \text { Peok Threshold: } & 1000 \\ \text { Peok Minimum: } & 50\end{array}$

Pump Time:

Dolo Role:

Smoolh:

Peok Threshold:

Peok Minimum:

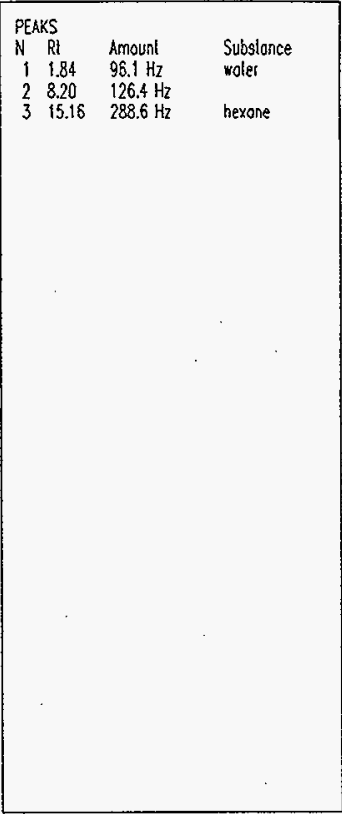


HNF-1861 Rev. 0

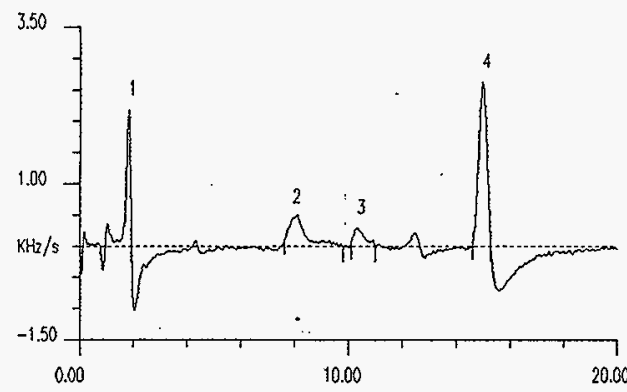

\begin{tabular}{|llll}
\hline \multicolumn{2}{l}{ PEAKS } & & \\
N & Rt & Amount & Subslonce \\
1 & 1.82 & $263.0 \mathrm{~Hz}$ & woteI \\
2 & 7.96 & $244.4 \mathrm{~Hz}$ & \\
3 & 10.35 & $127.3 \mathrm{~Hz}$ & \\
4 & 14.99 & $907.1 \mathrm{~Hz}$ & hexone
\end{tabular}

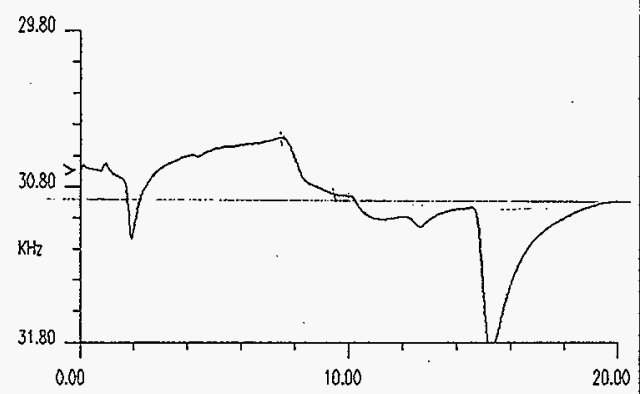

97091913.060

Noles

$\sqrt{7032-405-084}$

Woste Jank $[X-113$

No woter trop

$30 \mathrm{sec}$ somple time $27 \mathrm{cc} / \mathrm{min}$

$3 \mathrm{deg} / \mathrm{sec}$ to $85 \mathrm{deq}$

Sow 139

$15 / 40 / 70 / 80$

column $Q B-624$

Somple: see logbook WHC-N-1375, 5

$\begin{array}{ll}\text { File: } & 97091913.060 \\ \text { Time: } & \text { 13:06:09 } \\ \text { Oote: } & \text { 19-Sep-97 } \\ \text { Meihod: } & \text { twrst.mith } \\ \text { Peok: } & \text { iwrsi.pkd }\end{array}$

$\begin{array}{ll}\text { Pump Time: } & 30 . \\ \text { Dolo Rale: } & 20 \mathrm{~ms} / \text { point } \\ \text { Average: } & 1 \\ \text { Smoolh: } & 6 \\ \text { Peok Smooth: } & 2 \\ \text { Peok Threshold: } & 1000 \\ \text { Peok Winimum: } & 50\end{array}$

Sow Temp: $\quad 15.0$

Column Temp: $\quad 40.1$

Inlel Temp: $\quad 83.5$

Volve Temp: $\quad 70.9$

Trop Volloge: $\quad 59.8$

Sow Number 205.

vCO Frequency: $\quad 500.180 \mathrm{kHz}$ 


\section{HNF-1861 Rev. 0}

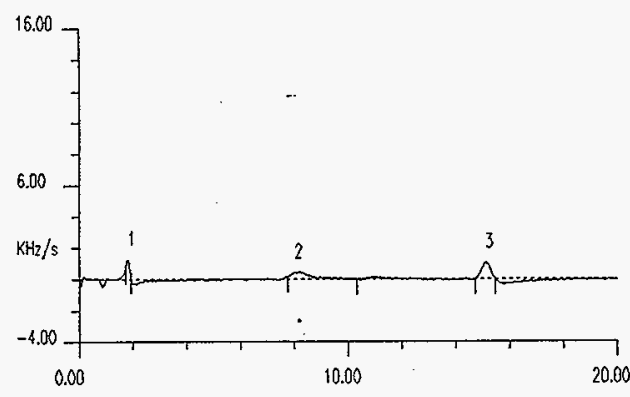

$$
\begin{array}{llll}
\text { PEAKS } & & \\
N & \mathrm{Rt} & \text { Amount } & \text { Substonce } \\
1 & 1.82 & 118.3 \mathrm{~Hz} & \text { woter } \\
-2 & 8.04 & 215.1 \mathrm{~Hz} & \\
3 & 15.12 & -381.4 \mathrm{~Hz} & \text { hexone }
\end{array}
$$$$
6.00
$$$$
0.00
$$

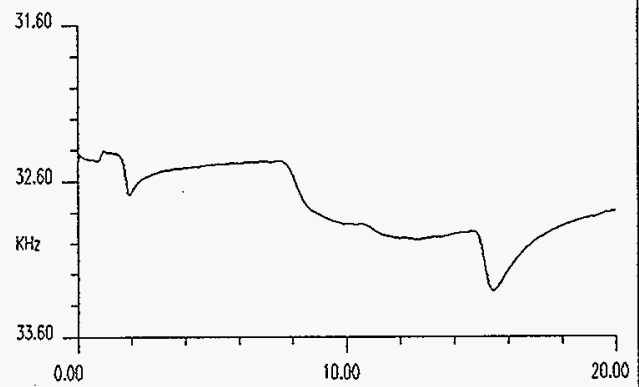

97091913.365

Notes

ท7020-805-0.55

Woste Tonk $S X-111$

No woter trop

30 sec somple time $27 \mathrm{cc} / \mathrm{min}$

$3 \mathrm{deg} / \mathrm{sec}$ to $85 \mathrm{deg}$

\begin{tabular}{|c|c|c|c|c|}
\hline $\begin{array}{l}\text { File: } \\
\text { Time: } \\
\text { Dole: } \\
\text { Welhod: } \\
\text { Peok: }\end{array}$ & $\begin{array}{l}97091913.365 \\
13: 36: 56 \\
19-5 e p-97 \\
\text { iwrsi.mith } \\
\text { fwrsi.pkd }\end{array}$ & $\begin{array}{l}\text { Pump Time: } \\
\text { Oolo Role: } \\
\text { Average: } \\
\text { Srrooth: } \\
\text { Peak Smooth: } \\
\text { Peok Threshold: } \\
\text { Peak Minimum: }\end{array}$ & $\begin{array}{l}30 . \\
20 \mathrm{~ms} / \text { point } \\
1 \\
6 \\
2 \\
1000 \\
50\end{array}$ & $\begin{array}{l}\text { Sow Temp: } \\
\text { Column Iemp: } \\
\text { Inlet Temp: } \\
\text { Volve Temp: } \\
\text { Irop Volloge: } \\
\text { Sow Number } \\
\text { VCO Frequency: }\end{array}$ \\
\hline
\end{tabular}

Sa* 139

$15 / 40 / 70 / 80$

column 08-624

Somple: see logbook $4 H C-N-1375,5$ 


\section{HNF-1861 Rev. 0}
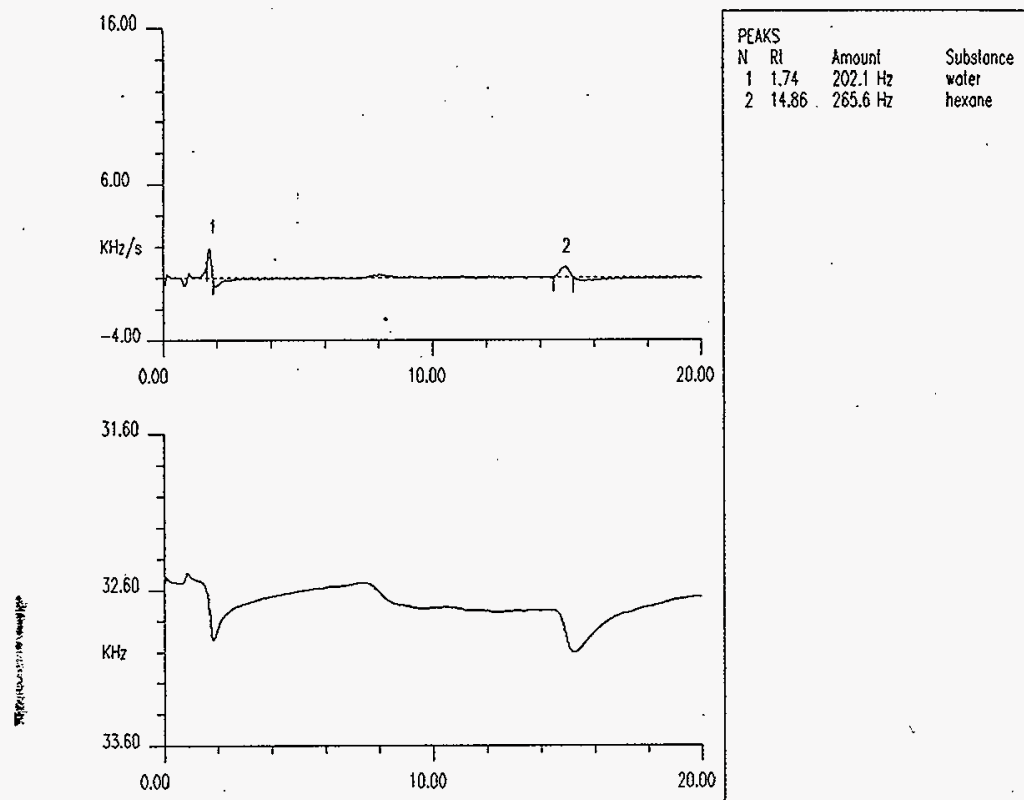

97091913.315

Noles

V7022-A05-041

Hoste Tonk $S K-112$

No wotet trop

$15 \mathrm{sec}$ somple time $27 \mathrm{cc} / \mathrm{min}$

$3 \mathrm{deg} / \mathrm{sec}$ to $85 \mathrm{deg}$

Sow 139

$15 / 40 / 70 / 80$

column $08-624$

Somple: see bogboak WHC-N-1375, 5

\begin{tabular}{|c|c|c|c|c|}
\hline $\begin{array}{l}\text { File: } \\
\text { Jime: } \\
\text { Dole: } \\
\text { Nethod: } \\
\text { Peok: }\end{array}$ & $\begin{array}{l}97091913.315 \\
13: 31: 56 \\
19-5 \text { ep-97 } \\
\text { 1wrst.mith } \\
\text { iwrsi pkd }\end{array}$ & $\begin{array}{l}\text { Pump Time: } \\
\text { Dalo Role: } \\
\text { Averoge: } \\
\text { Smooth: } \\
\text { Peok Smooth: } \\
\text { Peok Threshold: } \\
\text { Peok Minimum: }\end{array}$ & $\begin{array}{l}15 . \\
20 \mathrm{~ms} / \text { point } \\
1 \\
6 \\
2 \\
1000 \\
50\end{array}$ & $\begin{array}{l}\text { Sow Temp: } \\
\text { Column Temp: } \\
\text { Inlet Temp: } \\
\text { Volve Temp: } \\
\text { Trop Voltoge: } \\
\text { Sow Number: } \\
\text { VCO Frequency: }\end{array}$ \\
\hline
\end{tabular}




\section{HNF-1861 Rèv. 0}

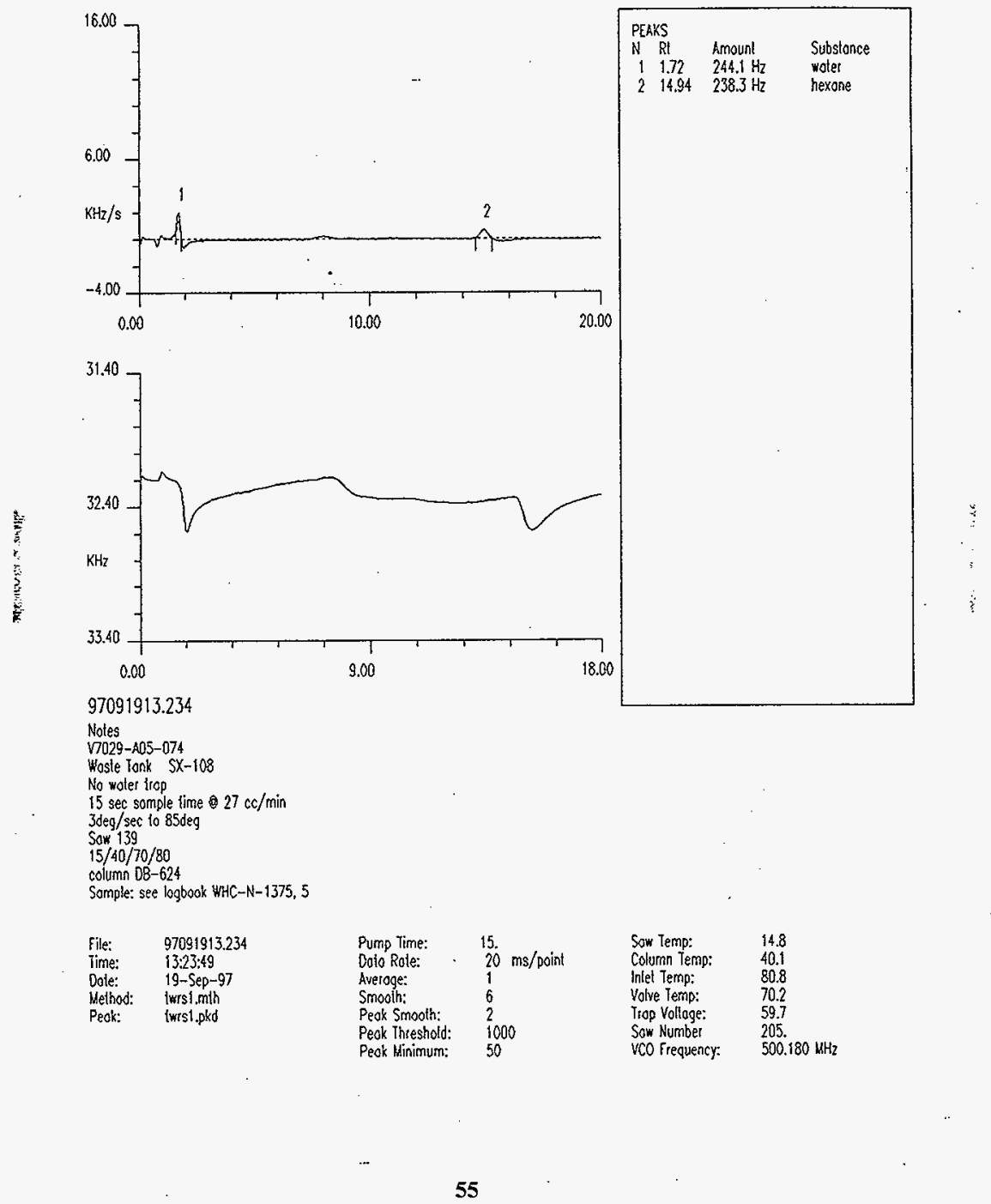


HNF-1861 Rev. 0
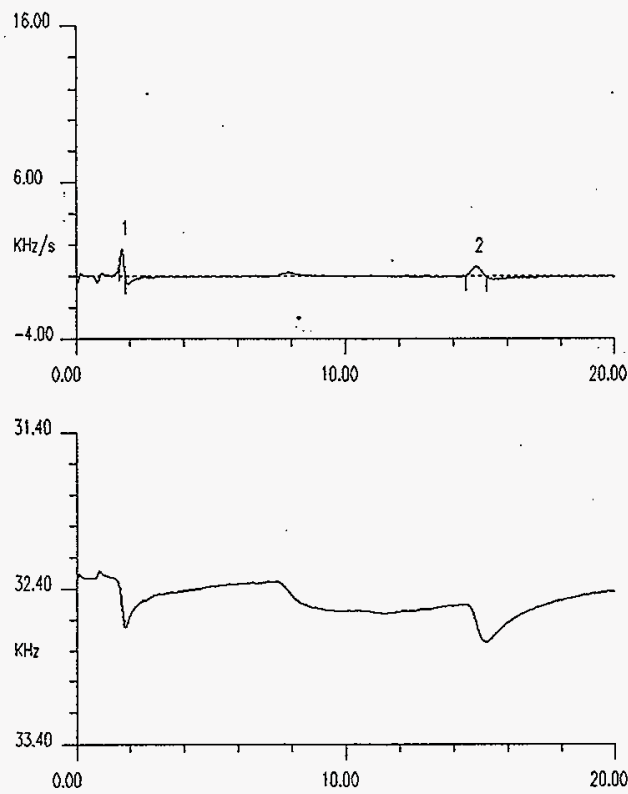

97091912.583

Notes

77023-A05-080

Wosle Tonk SX-114

No woter trop

i5 sec somple lime $27 \mathrm{cc} / \mathrm{min}$

$3 \mathrm{ded} / \mathrm{sec}$ to $85 \mathrm{deg}$

Sow 139

$15 / 40 / 70 / 80$

column DB-624

Somigle: see logbook WHC.N-N-1375, 5

File: $\quad 97091912583$

Time: $\quad 12.58: 34$

Dole: $\quad$ 19-Sep-97

Melhod: iwrsinth

Peok: $\quad$ iwrsl.pkd

$\begin{array}{llll}\text { Pump Time: } & 15 . & \text { Sow Temp: } & 14.8 \\ \text { Dolo Role: } & 20 \text { mis/point } & \text { Column Temp: } & 40.2 \\ \text { Averoge: } & 1 & \text { Inlet Temp: } & 80.1 \\ \text { Smooth: } & 6 & \text { Volve Temp: } & 70.2 \\ \text { Peok Smooth: } & 2 & \text { Trop Voltoge: } & 59.9 \\ \text { Peok Threshold: } & 1000 & \text { Sow Number } & 205 . \\ \text { Peok Minimum: } & 50 & \text { VCO Frequency: } & 500.180 \mathrm{HHz}\end{array}$


HNF-1861 Rev. 0
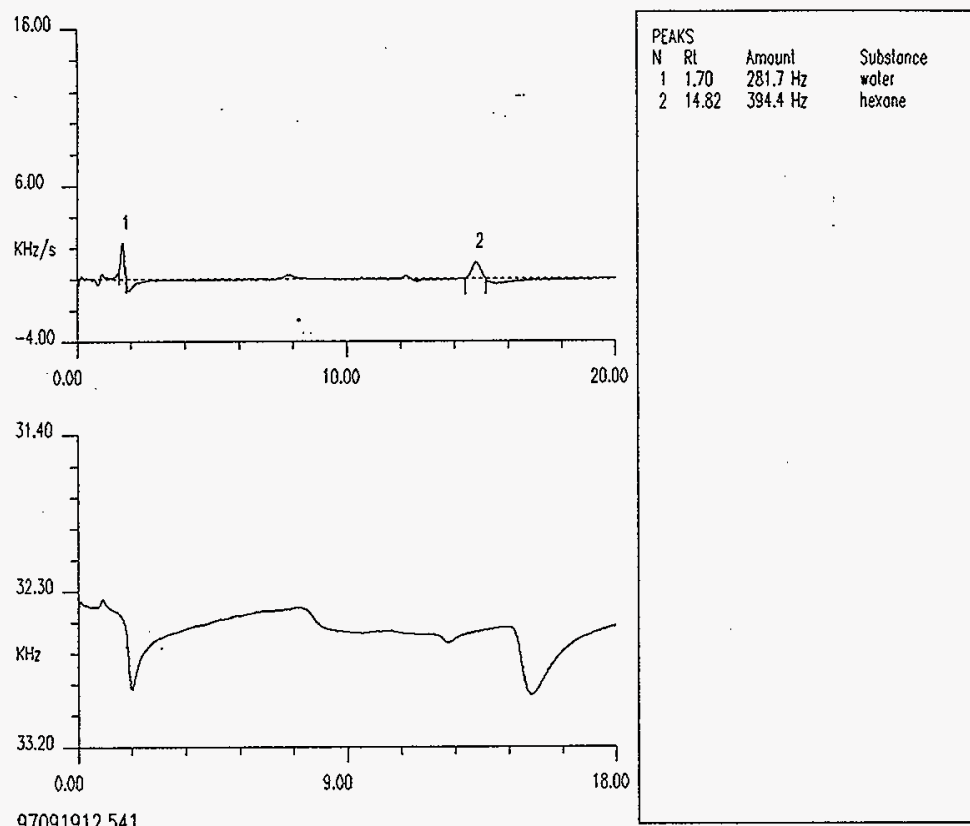

97091912.541

Notes

V7030-A.05-079

Wosie Tank SX-110

No water lrop

$15 \mathrm{sec}$ somple lime $27 \mathrm{cc} / \mathrm{min}$

$3 \mathrm{deg} / \mathrm{sec}$ to $85 \mathrm{deg}$

Sow 139

$15 / 40 / 70 / 80$

column $0 \mathrm{~B}-624$

Somple: see logbook WHC-N-1375, 5

\begin{tabular}{|c|c|c|c|c|}
\hline $\begin{array}{l}\text { File: } \\
\text { Time: } \\
\text { Dote: } \\
\text { Melhod: } \\
\text { Peok: }\end{array}$ & $\begin{array}{l}97091912.541 \\
12.54: 14 \\
19-\text { Sep-97 } \\
\text { twrsi.mith } \\
\text { lwisl.pkd }\end{array}$ & $\begin{array}{l}\text { Pump Time: } \\
\text { Dola Role: } \\
\text { Average: } \\
\text { Smooth: } \\
\text { Peok Smooth: } \\
\text { Peak Threshold: } \\
\text { Peok Minimum: }\end{array}$ & $\begin{array}{l}15 . \\
20 \mathrm{~ms} / \text { point } \\
1 \\
6 \\
2 \\
1000 \\
50\end{array}$ & $\begin{array}{l}\text { Sow Temp: } \\
\text { Column Temp: } \\
\text { Inlet Temp: } \\
\text { Valve Temp: } \\
\text { Trap Volloge: } \\
\text { Sow Numbet } \\
\text { vco Frequency: }\end{array}$ \\
\hline
\end{tabular}


HNF-1861 Rev. 0

APPENDIX D

STANDARD OPERATING PROCEDURE:

SCREENING AMBIENT ENVIRONMENTS FOR BTEX AND CHC COMPOUNDS USING GC/SAW FIELD PORTABLE GAS CHROMATOGRAPHS 


\section{Standard Operating Procedure Screening Ambient Environments for BTEX and CHC Compounds using GC/SAW Field Portable Gas Chromatograph}

\section{Introduction}

\subsection{Scope and Application}

1.1.1. This VOC Screening Method is used to determine the concentration of volatile organic hydrocarbons (VOCs) including the CHC's (chlorinated hydrocarbons) listed in Table I.

1.1.1. This sampling method uses Tedlar bags to collect volatile organic compounds (VOCs) samples from various sources of both ambient air, soil gas or any source of vapor that can be transferred to a Tedlar bag or sampled by the instrument directly. Soil gas measurements are limited to well tubes that do not penetrate into the water table. The porosity of the soil must allow the acquisition of sample without appreciably decreasing the pressure in the well.

1.1.2. This method is based on a headspace, fast gas chromatography procedure. This method should be

\begin{tabular}{|l|}
\multicolumn{1}{|c|}{ Analyte } \\
\hline Carbon Tetrachloride (CT) \\
\hline cis-Dichloroethylene (DCE) \\
\hline Chloroform (CF) \\
\hline Trichloroethylene (TCE) \\
\hline Tetrachloroethylene (PCE) \\
\hline $1,1,2,2$ Tetrachloroethane (TCA) \\
\hline Benzene (B) \\
\hline Toluene (T) \\
\hline Ethylbenzene (EB) \\
\hline O-Xylene (O-X) \\
\hline
\end{tabular}

Table I - List of Analytes used by, or under the supervision of, analysts experienced in the use of sampling techniques and gas chromatography. The analysts should be skilled in the interpretation of gas chromatograms and in the use of chromatograms as a quantitative tool.

1.1.3. The procedure described herein is applicable to the sampling of VOCs in approximately the .010 to $200 \mathrm{ppm}$ range. The lower limit is determined by the tedlar bag cleanliness, the specific analyte and the sampling time, the upper limit is determined by the compound vapor pressure.

\subsection{Limitations}

1.2.1 Source gas samples in Tedlar bags must be analyzed within 24 hours to get accurate results. The results in the procedure listed herein are specifically for but not limited to the compounds listed in Table I.

1.2.2 The method is limited by the ability of the instrument to resolve two compounds which may tend to coelute. Some knowledge of the compounds to be analyzed is required to assess the ability of the method to quantify analytes in the presence of coeluting compounds.

\section{Summary of VOC Screening Method}

2.1 The VOC Screening Method provides gas chromatographic conditions for the detection of volatile chlorinated hydrocarbons and volatile aromatics. A temperature program and narrow bore capillary column are used to separate these organic compounds. Detection is achieved by a Surface Acoustic Wave detector (SAW). Quantitation is based on comparative SAW response to a calibrated gas standards. The nominal conditions for VOC analysis are: Helium flow $-3 \mathrm{ccm}$, Sample flow -40 $\mathrm{cm}$, column at $40^{\circ} \mathrm{C}$ initially and ramped to $70^{\circ} \mathrm{C}$ at $5.5^{\circ} \mathrm{C} /$ sec. SAW temperature is $20^{\circ} \mathrm{C}$. 
HNF-1861 Rev. 0

2.2 The method is based upon the ability to sample a controlled volume of gas either from a tedlar bag or from other sources.

2.3 This method is suitable for the analysis of waters, soils, or wastes. Water samples can be analyzed directly for VOC's in the headspace volume of a septa vial (VOA vial) by gas chromatography. Soil or waste samples may first be extracted into methanol and then the headspace volume analyzed by direct or indirect methods. Direct desorption methods may also be used in which a headspace volume of vapor is generated suitable for examination with the instrument.

\section{Interferences}

3.1 Due to the universal detection capability of the SAW, other volatile organies may be detected by this method. It is implicit in the method as described that some prior knowledge of the types of chemical compounds likely to be encountered is known.

3.2 Impurities from organics outgassing from the plumbing ahead of the trap may lead to contamination. The system must be demonstrated to be free of contamination by the analysis of laboratory reagent (method) blarks. Use of low melting point plastics or those which are subject to the continuous leaching of volatiles should be avoided for making sample-tip connections to the instrument.

3.3 Contamination by carryover can occur whenever high-level and low-level samples are analyzed sequentially. To reduce carryover, the trap and other components may require purging and bake out following a high level sample. A simple precaution during field screening which is highly recommended is to run an air sample blank of known purity. the sampling syringes.

\subsection{Instrument Probe}

4.1.1. The instrument inlet is glass lined stainless steel for sampling of vapors directly into the instrument. Sampling of vapors from Tedlar bags is performed using the needle inlet which is slipped onto the front of the instrument via the luer fitting.

\subsection{Tedlar Sample Bags}

Sample are taken using 1 liter bags made of .002 inch Tedlar film. The bags must have a septum port and a push-pull type filling valve.

\subsection{Sampling Pump to fill Tedlar bags}

In the event that positive pressure is not available to fill tedlar bags, a pump must be used. The recommended pump is a KNF Neuberger, part number NO5STI, with stainless steel and Teflon wetted parts.

\subsection{Flow meter}

Use an Altrech or equivalent mass flow meter to measure sample flow. 
HNF-1861 Rev. 0

\subsection{Syringes}

Two types of syringes are required. A glass $20 \mathrm{ccm}$ gas tight syringe and a plastic or glass $500 \mathrm{ccm}$ gas tight syringe.

\subsection{Sample lines}

Teflon tubing, $6.4 \mathrm{~mm}$ (1/4 inch) outside diameter and of a length to connect the pump to the tedlar bag, not to exceed 6 feet. Silicone tubing, $6 \mathrm{~mm}$ inside diameter by $2.54 \mathrm{~cm}$ (1 inch) long to connect the $500 \mathrm{cc}$ syringe to the Tedlar bag.

\subsection{Expendable Materials}

4.7.1 Calibration Gas Standard gas mixtures for field spikes and calibration. The concentration of the cylinder should be 100 to 500 times the $\mathrm{PQL}$ of the instnument for the analyte of interest. The cylinder should not contain analytes that coelute during the analysis.

4.7.2 $99.999 \%$ purity Nitrogen Gas used to fill Tedlar bags for calibration

\section{Sample Collection}

\subsection{Ambient Samples}

Some situations allow the instrument to take a direct air sample. Some wells have septum port covers or caps which serve to isolate the well from the ambient environment. These wells can be sampled by using the instrument sample needle probe and piercing the septum while initiating the sample.

\subsection{Tedlar Bag Samples}

Some wells are pressurized by changes in ambient conditions which allow them to pressurize Tedlar bags directly. This technique avoids transfer through the sample pump.

\section{Procedure}

The following describes the procedure for collecting samples from wells or ambient air using Tedlar bags. A field blank and a field spike must be obtained for each test.

\subsection{Calibration}

6.1.1 A new initial calibration curve must be generated for each instrument, and the response factors entered into the Peak File, before analysis can begin. If the instrument has been previously calibrated in the lab, a single mid level calibration check only for each analyte is required. If the value of the check is within $30 \%$ of the lab value, then the response factor is confirmed. If the value is greater than $30 \%$, then the instrument must be recalibrated in the field.

6.1.2 Check instrument status. Measure the instrument sample flow using the mass flow meter. Record the sample flow and enter the value in the Peak File as directed below.

6.1.3 Run an instrument blank. Assure that the background is below $10 \mathrm{ppb}$ for any compounds in the peak file. The blank should be a sample from a tedlar bag filled with nitrogen.

6.1.4 Create a calibration bag. Fill a tedlar bag with calibration gas from the calibration gas cylinder using a piece of silicone tubing. The volume of gas in the bag is not important but should be between 250 and $500 \mathrm{ml}$. 
HNF-1861 Rev. 0

6.1.5 Create a midlevel spike bag. Fill the $500 \mathrm{ccm}$ syringe with nitrogen gas using the silicone tubing as a connection to the regulator. The regulator pressure should be set at a pressure of $1-5 \mathrm{psi}$. Open the regulator valve slowly and allow the syringe plunger to move until the syringe contains $500 \mathrm{ccm}$ nitrogen. Close the syringe valve before removing the bag from the cylinder. Inject the $500 \mathrm{ccm}$ of nitrogen into the 1 liter bag using the same silicone tube to interface between the bag and the syringe. Use the $100 \mathrm{cc}$ syringe to extract a volume of concentrated gas from the calibration bag. The volume will depend on the concentration required. Inject the sample into the bag filled with nitrogen and allow to sit for $\$-10$ minutes.

6.1.6 Calibrate the instrument. The working calibration curve or response factor must be verified by the analysis of a mid level calibration verification standard at least every 4 hours and at the beginning and end of an analytical sequence. Attach the calibration bag to the inlet of the instrument and initiate a cycle. Confirm that the value for the analyte is within the retention time window by denoting the identification of the analyte. If the analyte is detected and the measured response is within $30 \%$ of the predicted response, then the calibration verification is complete for that analyte.

\subsection{Peak File Setup}

6.2.1 Confirm the retention time windows for each component to be analyzed. Make three injections of the component and calculate the standard deviation of the retention time of each component. The retention time is set to the mean value of the three retention times and the window is $+/-3$ times the standard deviation expressed as a perceat of the mean retention time. Window $=3$ S.D.Mean X $100 \%$. Use the greater of this calculated value or $2.5 \%$.

6.2.2 Enter the sample flow rate. If the value measured is within $10 \%$ of the previous value, then the sample flow is nominal and the analysis can proceed. If it is outside these limits, then the sample train must be evaluated for blockage or restriction.

6.2.3 Record any changes in the Peak File in the instrument log.

\subsection{Sample Preparation}

6.3.1 Air Samples - Air samples that can be directly sampled by the instrument should be performed in that manner. Sample directly through the syringe tip by directing it toward or into the area to be analyzed.

6.3.2 Bag Samples - When direct sampling is not possible, Tedlar bags must be used. If the process to be monitored is at positive pressure, then the bag may be filled by directly attaching it to the process source and allowing the bag to fill to approximately half full. The actual volume is not important. Attach the bag with Teflon tubing, when possible, as silicone tubing may absorb some of the analyte during the transfer. After filling the bag, pierce the bag septum with the needle inlet and initiate the sampling cycle.

6.3.3 Bag Samples with Pump - The bag must be filled with a pump when the process is at pressures that are below or equal to atmospheric pressure. Attach the pump outlet to a bag using Tefion tubing. If the pump has not been previously cleared, a blank must be obtained. Fill a bag using the tubing to be used in the final process. The inlet tubing should be attached to a bag filled with nitrogen to simulate a clean process sample. If the blank shows no response to the analytes of interest, then the inlet tubing may be attached to the process and a new bag filled using the pump. After filling the bag, pierce the bag septum with needle inlet and initiate the sampling cycle. 


\section{HNF-1861 Rev. 0}

\subsection{GC Analysis}

6.4.1. Blank samples should be taken before each analytical run. Monitor the blank for background levels or carryover. Continue blanks until the levels are below preset minimums.

6.4.2. It is recommended that screening of the sample take place before full analysis begins to assure that the levels being detected are within the analytical method parameters.

6.4.3. The instrument should be used with the SAW/GC Method for which the calibration was performed. Use of any other method requires the generation of a new calibration curve.

\subsection{Calculations}

6.5.1 External Standard Calibration - The concentration of each analyte is read directly off of the screen of the instrument computer. The concentration is given in ppm or pg depending on the method of calibration. To get results in ppm, a known sample of analyte is analyzed and the instrument result is recorded in frequency units ( $\mathrm{Hz})$. The calibration factor is calculated by:

$$
\mathrm{CF}=\mathrm{F}_{\mathrm{c}} / \operatorname{conc} \times \mathrm{S}_{\mathrm{t}} / \mathrm{f}
$$

Where:

$$
\begin{aligned}
& \mathrm{CF}=\text { calibration factor, } \mathrm{Hz} / \mathrm{ppm} \cdot \mathrm{mL} \\
& \mathrm{F}_{\mathrm{c}}=\text { Signal in } \mathrm{Hz} \\
& \mathrm{S}_{\mathrm{t}}=\text { Sample Time } \\
& \mathrm{f}=\text { Sample flow rate }
\end{aligned}
$$

\section{Quality Control}

\subsection{Minimum required elements of quality control}

The minimum required elements of quality control are as follows:

$$
\begin{aligned}
& \text { Initial Demonistration of Proficiency (Section 7.2) } \\
& \text { Method Detection Limit Determination (Section 7.3) } \\
& \text { Analysis of Blank Samples (Section 7.4) } \\
& \text { Laboratory Control Sample Analysis (Section 7.5) }
\end{aligned}
$$

\subsection{Initial Demonstration of Proficiency}

7.2.1 Initial Demonstration of Proficiency is required when first validating a new SAW/GC method, and each time the method is modifjed withis allowed parameters of the method (i.e. columns, conditions, etc.), and for each analyst performing the test method using the SAW/GC.

7.2.2 Select a representative vapor concentration (approximately 10-20 times the estimated detection level- see Table 2) for all target analytes. Prepare a Tedlar bag sample according to the procedures described in Section 7.3. Analyze tedlar bag sample using at least 5 replicates as described in Section 4.0.

7.2.3 Calculate the percent Relative Standard Deviation (\%RSD) for the results of Section 1.2.2 and verify that it is less than $20 \%$. 


\section{HNF-1861 Rev. 0}

\subsection{Method Detection Limit (MDL)}

7.3.1. Method Detection Limits must be determined for each änalyte of interest.

7.3.2. A mixed component gas tank standard (Available from Scott Gas Co.) is to be used for MDL determination.

NOTE. MDL determination may be used as a substitute, for Initial

Demonstration of Proficiency (Section 1.1).

7.3.3. A minimum of seven separate vapor samples are to be analyzed at 2 - 5 times the estimated detection level. Results are to be assessed standard deviation (s).

$$
\left(\sigma_{s}\right) \quad \times 3.14=\mathrm{MDL}
$$

\subsection{Analysis of Blank Samples}

7.4.1. A Field Blank is required (Section 7.4) for each collection batch. The blank must be analyzed if target analytes are detected in any of the samples in the collection batch. If target analytes are detected in the Field Blank above Reporting Limits, results of the Field Blank analysis must be included in the final report. Correction for Field Blank contamination is not permitted.

\subsection{Laboratory Control Sample (LCS) Analysis}

7.5.1. A Laboratory Control Sample must be performed very 20 samples or at least once per analysis batch, which ever is more frequent.

7.5.2. The LCS must be prepared with a product mixture, or one that has been thoroughly evaluated by the laboratory. The LCS must be taken through all sample preparation procedures described in Section 7.0.

7.5.3. Acceptance criteria for the LCS is $30 \%$ of actual values.

Table I- Estimated Detection Limits

\begin{tabular}{|l|c|}
\hline Analyte & $\begin{array}{c}\text { EDL } \\
\text { (ppb) }\end{array}$ \\
\hline Carbon Tetrachloride (CT) & 70 \\
\hline cis-Dichloroethylene (DCE) & 110 \\
\hline Chloroform (CF) & 65 \\
\hline Trichloroethylene (TCE) & 10 \\
\hline Tetrachloroethylene (PCE) & 3 \\
\hline 1,1,2,2 Tetrachloroethane (TCA) & 1.3 \\
\hline Benzene (B) & 45 \\
\hline Toluene (T) & 4.5 \\
\hline Ethylbenzene (EB) & 2.0 \\
\hline O-Xylene (O-X) & 2.0 \\
\hline
\end{tabular}


HNF-1861 Rev. 0

APPENDIX E

SOL TESTING SUMMARY BY ELECTRONIC SENSOR TECHNOLOGY 
HNF-1861 Rev. 0

SoilTestSummary

$08 / 18 / 97$

\section{Soil Testing Summarv}

Screening of Soil containing BTEX and CHC Comporunds using a GC/SAW Portable Gas Chromatograph just got easier with the development of a thermal extraction tool for the instrument. The tool consists of a $6 \times 1 / 4$ inch quastz tube and a removable temperature controlled outer jacket. Soil to be analyzed is packed into the sample tube and attached directly to the luer inlet of the SAW/GC.

Recovery test results with validated spiking solutions have been excellent, typically $90-110 \%$. To eliminate errors in procedures involving dilution of liquid samples it was found necessary to validate the spiking solution with a certified vapor source.

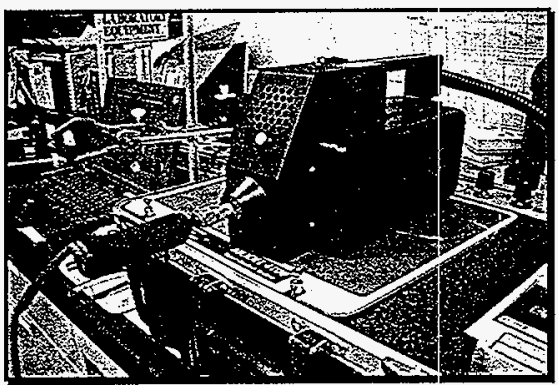

Figure 1-SAW/GC soil extraction attachment with outer temperature controlled heater jacket

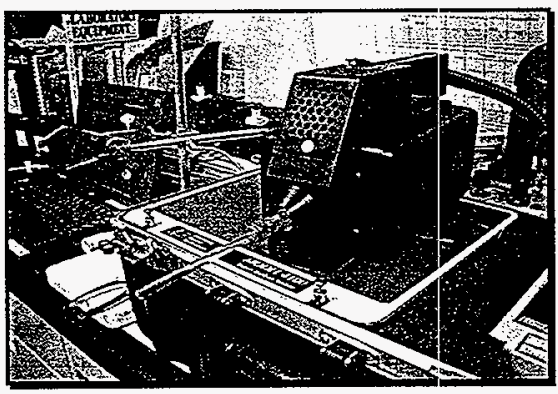

Figure 2- Quartz desorption tube of soil extraction apparatus. 
To measure the concentration of the spiking solution, tedlar bags containing analyte vapor concentrations are prepared as illustrate in Figure 3. Two bags are prepared. One contains analyte whose concentration is traceable to a certified gas tank. The other bag is prepared using a measured amount of diluted spiking solution of unknown or approximate concentration.

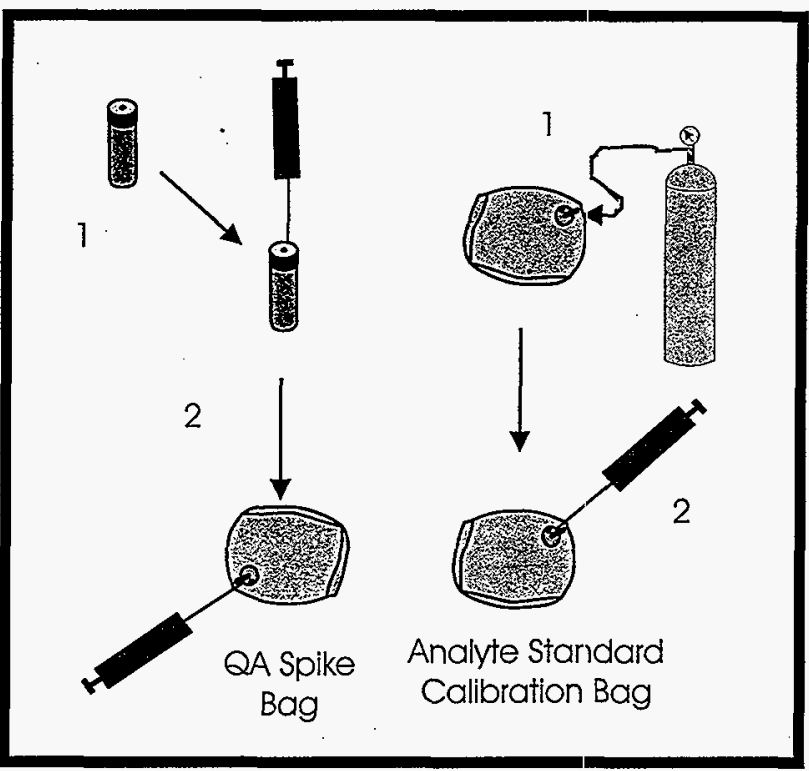

Figure 3- Preparation of tedlar bag analyte concentrations using certified gas tank and injection of spiking solution.

First the SAW/GC is calibrated using the tedlar bag containing the certified gas concentration (See Figure 4). Calibration enables the instrument to provide measurement results in either a vapor pressure or total mass extracted in nanograms or picograms. The bag containing the vapor prepared by injecting a known amount of spiking solution (in $\mu$ liters) is then measured by the SAW/GC. The SAW/GC measurement provides the mass concentration of the tedlar bag and knowing the total gas volume yields the total mass of analyte injected into the tedlar bag by the spiking solution. Dividing the total analyte mass by the amount injected yield the concentration of the spiking solution. 


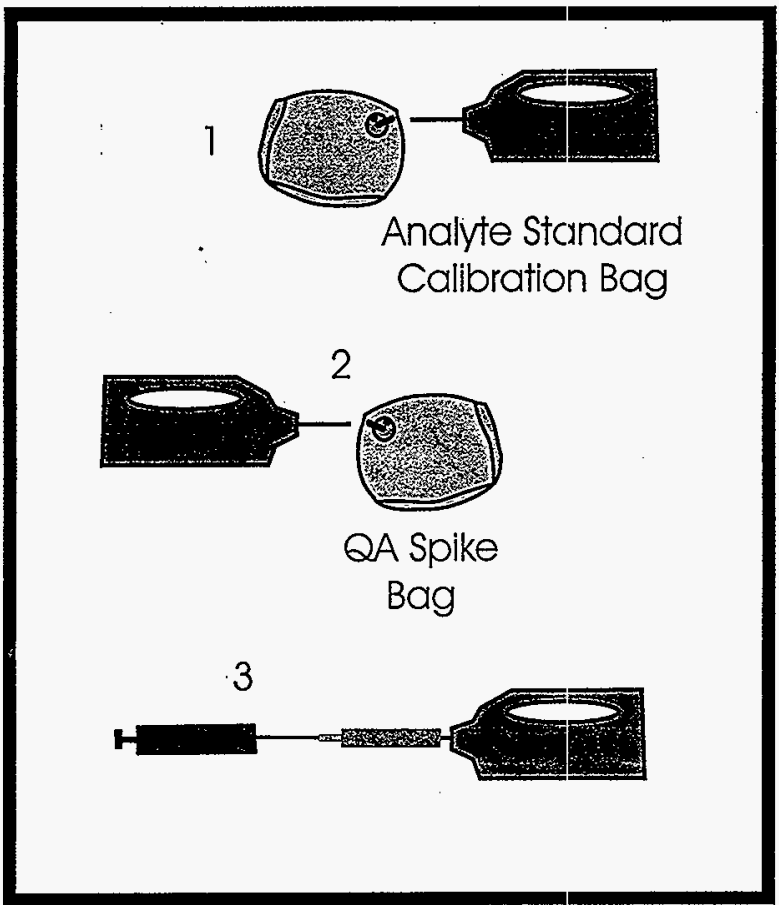

Figure 4-Calibration of SAW/GC enables determination of spiking solution concentration.

After the concentration of the spiking solution has been measured and validated it can be used to test recovery or calibrate the thermal extraction apparatus by directly injecting a known number of analyte nanograms and measuring the amount recovered by the SAW/GC. 
HNF-1861 Rev. 0

APPENDIX F

SENSITIVITY AND DETECTION OF TPH-G HYDROCARBONS USING THE 4100 FIELD PORTABLE GC INCORPORATING A SURFACE ACOUSTIC WAVE DETECTOR 
HNF-1861 Rev. 0

\section{Sensitivity and Detection of TPH-g Hydrocarbons using the 4100 Field Portable GC Incorporating a Surface Acoustic Wave Detector}

\section{Introduction}

An important role for gas chromatography (GC) is the detection and analysis of the chemical constituents of hydrocarbon fuels; gasoline and diesel. As these fuels contain a bighly complex mixture of several hundred discrete compounds, standardization and simplification procedures have been sought that can simplify the quantitation of these compounds. These methods are of particular interest when estimating the extent of contamination due to petroleum hydrocarbons as they impact the environment due to fuel spills and in particular Leaking Underground Fuel Tanks (LUFT).

The usual summarization of a fuel contamination issue as described by the analysis of gasoline components is as a TPH-g (Total Petroleum Hydrosarbon-gasoline) number. The higher molecular weight compounds commonly found in diesel fuels are similarly characterized by a TPH-d number (Total Petroleum Hydrocarbon-diesel). These two distinct numbers attempt to delineate the two most important hydrocarbon fuel sources in terms of the range of molecular weights into which the principle chemical components fall. TPH-g describes a lighter fuel with the chemical components ranging in carbon number from $\mathrm{C}_{s}$ to $\mathrm{C}_{12}$ (molecular weights from approximately $70-170 \mathrm{Da}$ ) whilst diesel is a heavier fuel with constituents ranging from $\mathrm{C}_{2}-\mathrm{C}_{20}$.

During laboratory analysis of gasoline and diesel contaminated matrices several protocols may be employed. Of specific interest is the California EPA (Environmental Protection Agency) LUFT Method 1000 which describes laboratory procedures for the analysis of hydrocarbon fuels. The US-EPA also provides laboratory methods described either as EPA Methods or more specifically derived from the SW846 protocols which can equally be used to describe environmentally derived hydrocarbon fuel concentrations.

The TPH numbers are usually derived by integrating the concentrations of a representative number of gasoline or diesel constituents. The constituents are chosen from a molecular weight range and are representative in terms of carton number which also usually reflects their elution order on a GC. Compilation of the signal strengths as derived from the GC analysis in terms of a total integration provides an estimate of TPH-g or TPH-d.

An important issue is revealed by the large difference in toxicity of the constituents of gasoline. Here a TPH- $\mathrm{g}$ number derived from integrating a range of pre-determined nalkanes may not truly reflect the significance of any environmental impact. This statement should be reviewed in terms of the relative toxicology of benzene and cetane. Gasoline is comprised of up to $12 \%$ of benzene which is a known liver carcinogen. Cetane represents the principal $C_{15}$ component of diesel and displays dramatically less toxicological properties. Because of these differences it has become important that chemical analysis should recognize by speciation the more environmentally sensitive components of hydrocarbon fuels. To this end, additional analyses for the so called BTEX (Benzene, Toluene, Ethylbenzene and Xylene) isomers provide essential additional information concerning environmental issues. 


\section{Discussion}

The 4100 SA $\ddot{W} / G C$ can provide fast on-site data relatirg to TPH-g and BTEX contamination. The GC can be optimized for the separation of the major components of gasoline using an appropriate column and software commands resident on a lap-top PC controlling temperature ramping and the temperature of the SAW detector.

The alkanes form an important group of compounds, the early members of which may be analyzed as IPH-g components. The SAW detector recognizes any chemical compound purely as a function of its volatility. The $\mathrm{C}_{6}-\mathrm{C}_{12}$ straight and branched chain hydrocarbons have volatilities that fall within a range that makes them suitable candidates for field detection and quantitation using the 4100SAW/GC.

The group of compounds shown below in table 1 have been chosen as representative of a TPH-g method. In addition to the alkane hydrocarbons two aromatic components from the BTEX group have been included to denonstrate the overlap in the method of separation and quantitation.

The following alkanes were separated using the $4100 \mathrm{SAW} / \mathrm{GC}$ as shown in table 1.

Table I-Creation of Calibrated Vapor Siource

\begin{tabular}{|l|l|c|}
\hline & \multicolumn{1}{|c|}{ Compound Name } & $\begin{array}{c}\text { uL of Liquid required in 10L Tedlar } \\
\text { bag for 100ppm Conc. }\end{array}$ \\
\hline 1 & n-Hexane & 6.15 \\
\hline 2 & $2,2,4$-Trimethylpentane (iso-octane) & 6.90 \\
\hline 3 & Toluene & 4.46 \\
\hline 4 & o-Xylene & 5.12 \\
\hline 5 & n-Dodecane & 9.54 \\
\hline
\end{tabular}

A method was developed which allowed an optimized separation of the compounds listed in table 1. The profile for this methods is shown as an instrument screen taken from the lap-top computer which controls the instrument arld is shown in Figure 1.

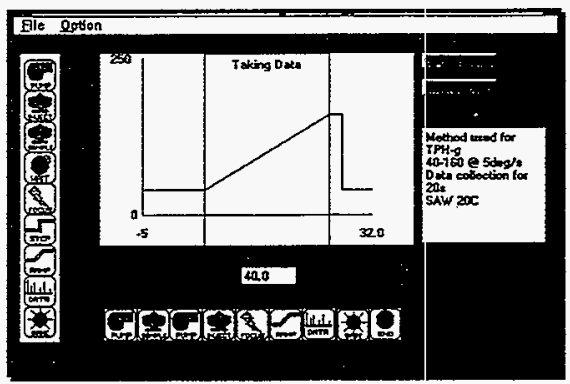

Figure 1- TPH method. 


\section{HNF-1861 Rev. 0}

The most volatile component of the table 1 list is hexane, this was also the component which had the least sensitivity when measured with the SAW at $18 \mathrm{C}$. The scaling factor for this compounds is 4.1 compared to the most sensitively detected compound which was $\mathbf{n}$-dodecane at 380 . These numbers correlate well with the physical properties of these compounds as n-hexane appears as a mobile low boiling point liquid (69C) compared to n-dodecane which is an oily high boiling point liquid (217C). The scaling factors are shown in the peak identification table as it is displayed from the PC screen in table 2.

- Table II- Peak Identification File.

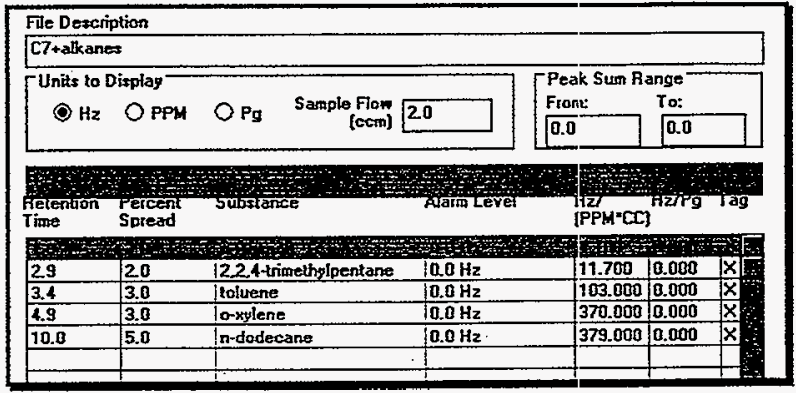

\section{Results}

The low molecular weight compounds produce well iefined chromatographic peaks, at the high end of the scale dodecane produces a slow eluting broad peak.

Iso-octane (2,2,4-trimethyl pentane) was chosen as a typical gasoline compound although it co-elutes with $\mathrm{n}$-heptane at $2.9 \mathrm{~s}$.

The BTEX components toluene and $o$-xylene were added to the alkane mixture to compare the chromatographic overlap and to encompass their importance as environmentally significant compounds. The detector response was far grater to these type of compounds and produced an LDL (lower detection linit) much lower than the early alkane homologues. Thus the LDL for hexane was 100ppm while for dodecane it was 10ppm and for toluene and xylene, 500ppm under the conditions of this analysis.

The linearity for n-bexane under a four point calibration analysis was shown in Figure 2. The plot shows the concentration in ppm on the ' $\mathrm{x}$ ' axis $v s$ the signal response in $\mathrm{Hz}$ on

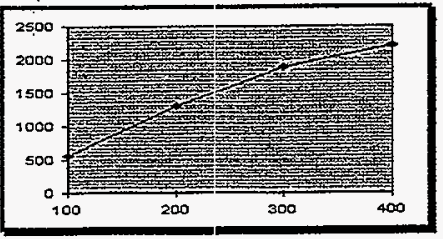

Figure 2- Four point culibration on n-hexane. 
the ' $y$ ' axis for Hexane. The retention times of the analytes remained stable over a minimum of two tries per concentration estimation as displayed by their \%RSD (data not shown).

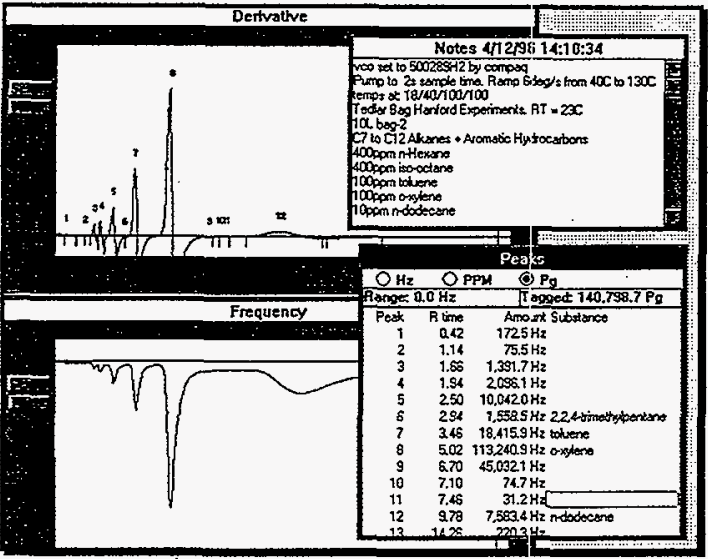

Figure 3-Alkane chromatogram.

A sample chromatogram taken with the SAW/GC using a calibrated mixture of alkanes is shown in Figure 3. By monitoring the total of tagged peaks the TPH number can be measured.

\section{Conclusion}

The 4100SAW/GC may be used either to survey an area. for the presence of fuel hydrocarbons in survey mode. Alternatively if the area is well characterized in terms of the hydrocarbon contaminants, the constituents may be quantitated by incorporating a known 4100 method into the analysis and controlling quantitation of the analytes by consistent reference to known standards. The $4100 \mathrm{SAW} / \mathrm{GC}$ can provide global integration over a suite of chromatographic peaks which may be linked to a known TPH-g number to provide information relating to environmental contamination with fuel bydrocarbons. In addition the environmentally sensitive compounds of the BTEX group may also be characterized and related to overall hydrocarbon contamination. 
HNF-1861 Rev, 0

APPENDIX G

RAPID SCREENING FOR POLYCHLORINATED BIPHENYLS AND 2,3,7,8- DIOXIN IN SOIL AND FLYASH USING A SAW/GC 
HNF-1861 Rev. 0

EPA Technology Validation

EST_Pcb.doc

\section{Rapid Screening for Polychlorinated Biphenyl and 2,3,7,8 Dioxin in Soil and Flyash Using a SAW/GC}

\section{Introduction}

A handheld portable chromatography system equipped with a non-specific Surface Acoustic Wave (SAW) detector is used to speciate and quantify PCB and dioxin contamination in soil and flyash with a 10 second analysis time. The SAW detector is an integrating mass detector (micro-balance) with zero dead volume and the ability to quantify chromatography peaks at the picogram level and with peak widths measured in milliseconds. Measurement speed and accuracy make the instrument well suited to rapid screening of soil samples. Early separation of those soil samples below the regulatory level from those which require laboratory validation with a GC/MS reduces the cost associated with site characterization and monitoring. The SAW/GC screening procedure, when incorporated into EPA. Methods (e.g. 8080), allows for pre-dilution's optimized to the limited dynamic tange of a GC/MS laboratory instrument.

A sampling pump and loop trap are used to sample and inject analyte into a GC capillary column. Speciation is based upon retention time measurements using a temperature programmed DB-5 column. Quantification is based upon the frequency shift produced by analytes or PCB isomers as they exit the GC column. By focusing the effluent onto a specific area on the surface of a temperature controlled piezoelectric crystal, high sensitivity is achieved with a 10 second analysis time. The SAW/GC is able to selectively screen and quantify PCB levels for dioxins and Aroclor compounds in soil and flyash with ppb precision.

Two procedures for extracting PCBs from soil matrices are used. These procedures have been tested on the dioxin and Aroclor mixtures shown. The first procedure uses an open tubular direct desorption tube (OTDDT) held at approximately $200^{\circ} \mathrm{C}$. The desorption tube is pre-packed with a soil sample and attached to the inlet of the SAW/GC. Heat is used to desorb vapors from a soil while the sampling pump of the SAW/GC collects the desorbed vapors. Total extraction by direct desorption is a fast and accurate method for soils with contamination levels below $250 \mathrm{ppb}$.

\begin{tabular}{|c|}
\hline Analytes Tested \\
\hline Aroclor 1221 \\
\hline Aroclor 1016 \\
\hline Aroclor 1248 \\
\hline Aroclor 1232 \\
\hline Aroclor 1242 \\
\hline Aroclor 1254 \\
\hline Aroclor 1260 \\
\hline Aroclor 1262 \\
\hline $2,3,7,8$ Dioxin \\
\hline
\end{tabular}

The second procedure is best suited to testing soil with contamination levels of $250 \mathrm{ppb}$ or higher because of the sample dilution inherent in the method. A liquid extraction of the soil using a mixture of hexane, water, and methanol is first carried out and then a small amount of the liquid extract is injected into the SAW/GC inlet and the $\mathrm{PCB}$ content measured. 


\section{HNF-1861 Rev, 0}

These methods should be used by, or under the supervision of, analysts experienced in the use of sampling techniques and gas chromatography. The analysts should also be skilled in the interpretation of gas chromatograms and in the use of chromatography as a quantitative tool.

The accuracy of the SAW/GC PCB/dioxin soil screening method is based upon npoint calibrations using Standard solutions. Quality assurance measurements require GC validation using only standards certified by an independent laboratory. All spiking solutions, prior to their use in soil recovery analyses or calibration by direct injection, must first be validated by $\mathrm{GC}$ measurement.

\section{Interference}

Due to the universal detection capability of the SAW detector, other non-PCB compounds may co-elute with PCB standards. Any such compounds detected may be misidentified and quantified as a PCB. If the quantification level is above the alarm threshold, the method requires the soil sample to be laboratory tested and the SAW/GC screening measurement validated. It is implicit in a screening method that there are no false negatives and that all positive responses require laboratory validation.

Impurities from contaminants within the instrument or inlet train desorption tubing may interfere. Contamination by carryover can also occur whenever high-level and low-level samples are analyzed sequentially. To insure against interference, the screening method requires that acceptable (method) blanks be recorded before and after all measurements

\section{Quality Control}

The minimum required elements of quality control ars as follows:

1. Initial Demonstration of Proficiency

2. Method Detection Limit Determination

3. Analysis of Blank Samples

4. Laboratory Control Sample Analysis

\section{Expendable Materials}

Laboratory Standard PCB-hexane solutions for field spikes and calibration. The concentration of the standaros should provide nanogram quantities of $\mathrm{PCB}$ when injecting 1 to $10 \mu$ liters of standard solution. A supply of reagent grade hexane is required for method blanks.

A pre-mixed supply of hexane, methanol, and water is required for performing liquid soil extractions. Other expendable items include septa equipped vials and pipette filters for filtering soil extractions.

\section{Weighing Balance}

A weighing balance accurate to $0.1 \mathrm{mg}$ is required to weigh the soil samples. 


\section{HNF-1861 Rev. 0}

EPA Technology Validation

EST_Pcb.doc

\section{Syringes}

To create soil audit samples for recovery confirmation, spiking solutions and quality assurance calibrations, a standard chromatography " syringe is used. Recommended is a $10 \mu$ liter syringe available from SGE, 10R-GT, Part No. 002250.

\section{Soil Samples}

For the direct thermal desorption method a soil sample collection consists of placing homogeneous samples (approximately $0.1-0.25$ grams) from a source to be analyzed into pre-weighed $6 \times 1 / 4$ inch glass tubes. For the liquid extraction method soil samples are placed in $4 \mathrm{~mL}$ glass vials with septa caps. Sampling spatula or other utensils which come into contact with the soil should be clean so as not to contaminate the sample. If the content of the soil is not to be measured immediately the ends of the glass tube are sealed with slip-on septa covers.

\section{Procedure No. 1 - Direct Thermal Extraction (DTE)}

The SAW/GC inlet sample port is glass lined stainless steel for sampling of vapors directly into the instrument. Total extraction from soil is performed using an open heated glass tube fitted with a glass-to-luer adapter attached directly to the inlet of the instrument. Calibration is performed using a syringe needle to inject laboratory standard solutions directly into the open tubular desorption tube.

\section{GC Analysis}

1. Take Blank samples before and after each analytical run. Monitor the blank for background levels or carryover. Continue blanks until the levels are below preset minimums. Each sample tube is weighed and pre-screened before loading with soil.

2. The instrument should be used with the SAW/GC Method and instrument settings for which the calibration was performed. Use of any other method requires the generation of a new calibration curve. The operator must save all chromatograms ( $\mathrm{SAV}-\mathrm{ALL}=\mathrm{ON}$ ), including blanks and calibration checks performed with liquid standards.

3. After loading tube with approximately $250 \mathrm{mg}$ of soil, attach luer adapter to one end of sample tube. Attach the sample tube to the luer inlet fitting of the SAW/GC.

4. Slide heater jacket, pre-heated to $200^{\circ} \mathrm{C}$, over the sample tube and immediately initiate soil sampling with sample time set to 30 seconds. Repeat 30 second soil sampling at 1 minute intervals until analyte concentration readings are less then $10 \%$ of initial sample values. Record the concentration mass, in nanograms, for each sample measurement, $\mathrm{N}_{\mathrm{i}}$ as well as the total of all sample measurements, $\mathrm{N}_{\mathrm{r}}$.

5. Measure the weight of the sample tube packed with soil. Subtract the weight of the empty tube and designate the result as $\mathrm{W}_{\text {sor }}$ in grams.. 
HNF-1861 Rev. 0

EPA Technology Validation

EST_Pcb.doc

\section{Procedure No. 2 - Liquid Extraction and Injection}

This method is well suited to analysis of soils with high concentrations of PCBs. First the PCBs are extracted from the soil using a mixture of hexane, methanol, and water.

1. Add a weighed amount of soil ( $0.25-1 \mathrm{gram})$ to $1 \mathrm{~mL}$ of solution, shake until soil is well dispersed, and let stand until hexane solute is clearly seen to separate and float on top of methanol-water layer with soil sediment resting on bottom of vial.

2. Extract approximately $0.25 \mathrm{~mL}$ of the hexane and use a disposable pipette filter to transfer into a clean vial and seal with septa cap.

Sampling of the extract solution is performed using an open tubular thermal desorption tube packed with glass wool. The tube is fitted with a glass-to-luer adapter which attaches directly to the inlet of the instrument. Calibration is performed using a syringe needle to inject laboratory standard solutions directly into the open tubular desorption tube.

\section{GC Analysis}

1. Take Blank samples before and after each analytical run. Monitor the blank for background levels or carryover. Continue blanks until the levels are below preset minimums. Each sample tube is weighed and pre-screened before loading with soil.

2. The instrument should be used with the SAW/GC Method and instrument settings for which the calibration was performed. Use of any other method requires the generation of a new calibration curve. The operator must save all chromatograms ( $\mathrm{SAV}-\mathrm{ALL}=\mathrm{ON}$ ), including blanks and calibration checks performed with liquid standards.

3. With the heater jacket removed and the extraction tube at room temperature inject a measured amount of extract into the tube. Initiate analysis runs with the SAW/GC to remove volatile compounds and until liquid can no longer be seen in the glass tube

4. Slide heater jacket, pre-heated to $200^{\circ} \mathrm{C}$, over the sample tube and immediately initiate sampling with sample time set to 30 seconds. Repeat 30 second sampling at 1 minute intervals until analyte concentration readings are less then $10 \%$ of initial sample values. Record the concentration mass, in nanograms, for each sample measurement, $\mathrm{N}_{\mathrm{i}}$, as well as the total of all sample measurements, $\mathrm{N}_{\mathrm{T}}$. 
HNF-1861 Rev. 0

EPA Technology Validation

EST_Pcb.doc

\section{Calculations}

Windows 95, SAW/GC system software (Version 4.0), and Excel and is required to operate the system, log data, and provide measurement docurnentation. With the system software, three calibration options are provided. The operator may select individual compound peaks and calibrate based upon the measured signal in $\mathrm{Hz}$ and the standard input in nanograms. Alternately the operator may select to use either the total area of all peaks over a specified range of retention times, or the sum of a set of 'tagged' peaks specified in a calibration file, to determine a response factor in terms of a standard input.

Soil contamination is expressed in either $\mathrm{ppm}(\mathrm{mg} / \mathrm{kg})$, $\mathrm{ppb}(\mu \mathrm{g} / \mathrm{kg})$, or ppt $(\mathrm{ng} / \mathrm{kg})$. To calculate soil contamination perform the following calculation:

$$
\text { Conc }_{\text {SOIL }}=\frac{\sum_{i} N_{i}}{W_{\text {SOIL }}}=\frac{N_{T}}{W_{\text {SOIL }}}
$$

For liquid extractions the above result must be multiplied by the ratio of the total amount of hexane solution divided by the amount of solution extract injected (dilution ratio).

\section{Instrument Calibration Procedure}

A calibration curve and the response factors must be entered into the Peak File software dialog screen, before analysis can begin. If the instrument has been previously calibrated in the lab, only a single mid level calibration check for each analyte is required. If the value of the check is within $30 \%$ of the lab value, then the response factor is confirmed. If the value is greater than $30 \%$, then the instrument must be re-calibrated.

Check instrument status. Measure the instrument sample flow using the mass flow meter. Record the sample flow and enter the value in the Peak File software dialog screen under sample flow in $\mathrm{ccm}$ (cc/min) units.

Run an instrument blank. Assure that the background is below $10 \mathrm{ppb}$ for any compounds in the peak file. The blank should be a method injection into an empty desorption tube.

Create a calibration standard solution. Fill a $4 \mathrm{~mL}$ vial with an appropriate amount of standard solution and an appropriate amount of solute so that a concentration (nanograms/ $\mu$ liter) which is mid-level to the desired measurement range, is achieved. Seal the vial with a new șepta lid.

To define the instrument response factor, $\mathrm{SF}$ (in $\mathrm{Hz} /$ picogram), a liquid injection into the desorption trbe with a known standard is made The instrument reading, $F_{m}$, in measurement units of frequency $(\mathrm{Hz} z=\mathrm{Hert} z)$ and the total amourt of analyte injected, $\mathrm{M}_{\mathrm{a}}$, in picograms defines the response factor:

$$
S F=\frac{F_{m}}{M_{a}}
$$




\section{HNF-1861 Rèv. 0}

EPA Technology Validation

EST_Pcb.doc

Note: If the proper scale factor is entered into the peak file dialog screen, the software will display PCB or dioxin measurement in picograms or nanograms in the peak window. An example using a $1 \mu$ liter injection with a solution of 10 nanogram $/ \mu$ liter $2,3,7,8$ dioxin is shown in Figure 1 .

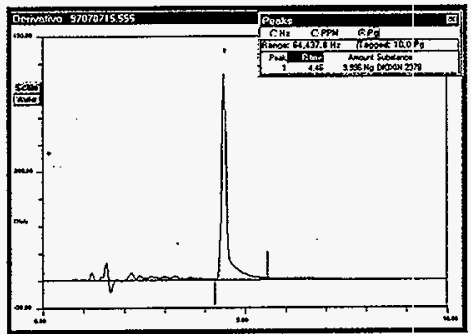

Figure 1- Calibration with 10 nanograms of $2,3,7,8$ dioxin.

\section{Peak File Setup}

Confirm the retention time windows for each component to be analyzed. Make three injections of the component and calculate the standard deviation of the retention time of each component. The average retention time and response factor for each analyte is entered into the peak recognition file.

PCB Aroclor mixtures typically contain 15 or more isomers as shown in Figure 2. In this case the system software provides the operator with the ability to use either the sum of peaks over a retention time range or the sum of a selected peaks, as the basis for calibration. A single average response factor for the sum of the peaks within the mixture is used to calculate the concentration of the Aroclor mixture.

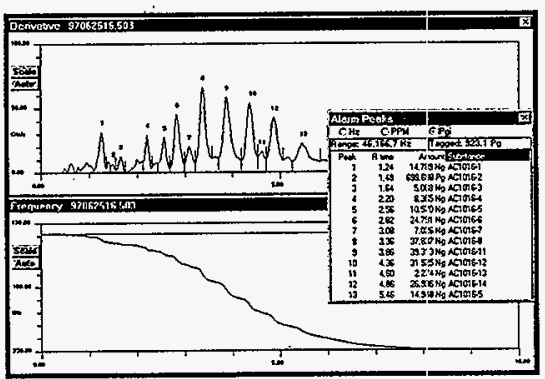

Figure 2-Calibration with Aroclor 1016. 


\section{HNF-1861 Rev. 0}

EPA Technology Validation

EST_Pcb.doc

\section{Aroclor Pattern Recognition}

Commercial Aroclor mixtures of PCB isomers are commonly found at environmental sites and their composition and vapor signature can readily be recognized by a trained operator. Five different Aroclor vapor signatures in vertically offset chromatograms are shown in Figure 3.

By creating peak identification files for the Arockor mixtures, the pattern

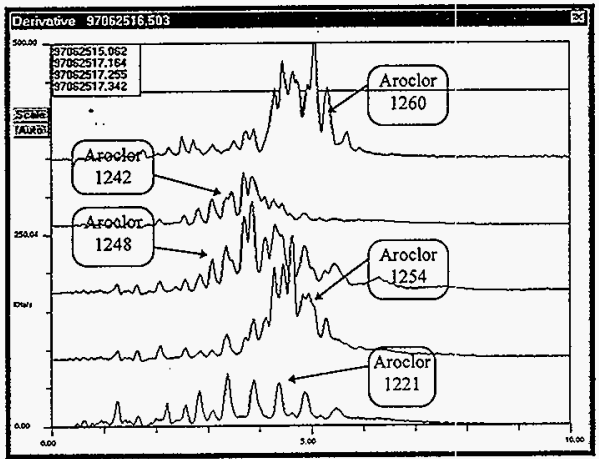

Figure 3- Vapor signatures of several Aroclor mixtures.

recognition process can be quantified and the relative degree of fit for an unknown set of PCB peak retention time determined. Data logging to Excel spread sheets using different peak recognition file pattems for the raw data, provides documentation and archival of all SAW/GC measurements. 
HNF-1861 Rev. 0

This page intentionally left blank. 


\section{DISTRIBUTION SHEET}

\begin{tabular}{|c|c|c|c|c|c|}
\hline \multirow{2}{*}{$\begin{array}{l}\text { To } \\
\text { Distribution }\end{array}$} & \multirow{2}{*}{\multicolumn{3}{|c|}{$\begin{array}{l}\text { From } \\
\text { Special Analytical Support }\end{array}$}} & \multicolumn{2}{|l|}{ Page 1 of 1} \\
\hline & & & & \multicolumn{2}{|c|}{ Date $12 / 23 / 97$} \\
\hline \multirow{2}{*}{\multicolumn{4}{|c|}{$\begin{array}{l}\text { Project Title/Work Order } \\
\text { Evaluation of a Gas Chromatograph with a Novel Surface Acoustic } \\
\text { Wave Detector (SAW GC) for Screening of Volatile Organic } \\
\text { Compounds in Hanford Waste Tank Samples }\end{array}$}} & \multicolumn{2}{|c|}{ EDT No. 620341} \\
\hline & & & & \multicolumn{2}{|l|}{ ECN No. } \\
\hline \multicolumn{2}{|l|}{ Name } & $\begin{array}{c}\text { Text } \\
\text { With All } \\
\text { Attach. }\end{array}$ & Text Only & $\begin{array}{l}\text { Attach./ } \\
\text { Appendix } \\
\text { Only }\end{array}$ & $\begin{array}{l}\text { EDT/ECN } \\
\text { Only }\end{array}$ \\
\hline C. A. Babel & $S 7-54$ & $x$ & & & \\
\hline C. Dormant & S3-90 & & & & $x$ \\
\hline L. L. Lockrem & $53-90$ & & & & $x$ \\
\hline L. M. Sasaki & $\mathrm{R} 2-12$ & $x$ & & & \\
\hline R. S. Viswanath & $\$ 3-90$ & & & & $x$ \\
\hline Central Files & $A 3-88$ & $x$ & & & \\
\hline SAS Files & $\$ 3-90$ & $x$ & & & \\
\hline
\end{tabular}

